\title{
Representation of Rossby wave propagation and its effect on the teleconnection between the Indian summer monsoon and extratropical rainfall in the Met Office Unified Model
}

\section{Xinxin Tang}

Ocean University of China

Jianping Li ( $\sim$ ljp@ouc.edu.cn )

Ocean University of China https://orcid.org/0000-0003-0625-1575

Huqiang Zhang

Australian Bureau of Meteorology

Sen Zhao

University of Hawai'i at Manoa

\section{Research Article}

Keywords: Rossby wave, Indian summer monsoon rainfall, Interhemispheric teleconnection, Meridional wind, Met Office Unified Model

Posted Date: May 28th, 2021

DOI: https://doi.org/10.21203/rs.3.rs-255748/v1

License: (c) (1) This work is licensed under a Creative Commons Attribution 4.0 International License. Read Full License

Version of Record: A version of this preprint was published at Climate Dynamics on September 13th, 2021. See the published version at https://doi.org/10.1007/s00382-021-05940-4. 
4

Representation of Rossby wave propagation and its effect on the teleconnection between the Indian summer monsoon and extratropical rainfall in the Met Office Unified Model

\author{
Xinxin Tang ${ }^{1}$, Jianping $\mathrm{Li}^{1,2,3^{*}}$, Huqiang Zhang ${ }^{4}$ and Sen $Z$ hao ${ }^{3}$ \\ ${ }^{1}$ Frontiers Science Center for Deep Ocean Multispheres and Earth System (FDOMES)/Key \\ Laboratory of Physical Oceanography/Institute for Advanced Ocean Studies, Ocean University of \\ China, Qingdao 266100, China. \\ ${ }^{2}$ Laboratory for Ocean Dynamics and Climate, Pilot Qingdao National Laboratory for Marine \\ Science and Technology, Qingdao 266237, China. \\ ${ }^{3}$ Department of Atmospheric Sciences, University of Hawai'i at Mānoa, Honolulu, HI 96822, USA \\ ${ }^{4}$ Bureau of Meteorology, GPO Box 1289k, Melbourne, VIC, 3001, Australia.
}

\title{
Corresponding author:
}

Prof. Jianping Li,

* Email: lipp@ouc.edu.cn

* ORCID: 0000-0003-0625-1575

Submitted to Climate Dynamics

Keywords: Rossby wave, Indian summer monsoon rainfall, Interhemispheric teleconnection, Meridional wind, Met Office Unified Model. 

(UM), the dry bias over the Indian monsoon region in Global Atmosphere 7 (GA7) is significantly reduced. However, the physical processes controlling how this reduced dry bias in India influences rainfall teleconnections in the extratropics remain unclear. Thus, in this study, we use Rossby wave tracing in a horizontally nonuniform background flow to investigate how the improved simulation of monsoon rainfall in GA7 compared with GA6 affects extratropical rainfall teleconnections. We find that wave rays emanating from the upper troposphere in the Indian monsoon region first propagate westward, then divide into the Northern Hemisphere $(\mathrm{NH})$ subtropical westerlies over Asia and the Southern Hemisphere (SH) subtropical westerlies. The wave ray trajectories in GA7 in years of strong Indian summer monsoon rainfall (ISMR) are closer to observations than those in GA6. We also find that the upper tropospheric meridional winds over the South Asian monsoon region and western Tibetan Plateau are much better simulated in GA7 than in GA6 owning to the improvement of ISMR and South Asian High (SAH), which leads to a more realistic simulation of the wave rays in GA7. The better simulated circulation teleconnections in GA7 then modulate the vertical motion and moisture transport, and hence affect extratropical rainfall anomalies in the $\mathrm{NH}$ and $\mathrm{SH}$. This paper provides new insights for the assessment of tropical-extratropical teleconnections in models. 


\section{Introduction}

The Unified Model (UM) is the atmospheric component of the numerical modelling system created by the UK Met Office (UKMO) for both weather and climate applications (https://www.metoffice.gov.uk/research/modelling-systems). It is widely used by many organizations and agencies around the world, particularly in the Australian-Asian region, including Australia, India, Korea, and the Philippines (https://www.metoffice.gov.uk/research/approach/collaboration/unifiedmodel/partnership). Two versions of the UM, namely the UM Global Atmosphere 6 (GA6) and 7 (GA7) are being used by the UK and Australia to contribute to the Intergovernmental Panel on Climate Change (IPCC) Coupled Model Intercomparison Project (CMIP6) (Hirst, 2015; Walters et al., 2019) and in their operational seasonal forecast systems (MacLachlan et al., 2015; Hudson et al., 2017). As a result, assessing the performance of the UM GA in the Australian-Asian monsoon region has been an important topic of past research.

As noted in previous UM assessments (Walters et al., 2014, 2017, 2019), the UM has a climatological rainfall deficit over the Indian subcontinent. However, the simulation of Indian summer monsoon rainfall (ISMR) within a given UM configuration was shown to improve when the model resolution was increased (Prakash et al., 2016; Jin et al., 2019). In a recent UM GA assessment study, Jin et al. (2019) showed that the area-averaged summer monsoon rainfall over the Indian subcontinent $\left(70^{\circ}-90^{\circ} \mathrm{E}, 5^{\circ}-25^{\circ} \mathrm{N}\right)$ was significantly increased in GA7 compared with GA6. Furthermore, the increased ISMR in GA7 with N216 resolution improved monsoon- 
desert rainfall teleconnections and generated more realistic remote rainfall correlation patterns in the Australian-Asian region. Part of the teleconnection patterns showed similarity with Rossby wave propagation from the tropics into the middle and high latitudes. However, as acknowledged by the authors, the underlying physical and dynamic processes supporting these improved rainfall teleconnection patterns and the increased ISMR in the simulations was not fully explored (Jin et al., 2019). The major goal of this study is therefore to further investigate how the simulation of Indian monsoon rainfall in GA6 and GA7 (Walters et al., 2017, 2019) affects the representation of tropical-extratropical rainfall teleconnections, and the nature of the underlying physical and dynamical processes. This analysis will also help to better understand the simulated current and future climate in these models in preparation for CMIP6.

The extratropical atmospheric response to tropical localized forcing is well established in both the Northern Hemisphere (NH) (Nitta, 1987; Hoskins and Rodwell, 1995; Rodwell and Hoskins, 1996; Kripalani et al., 1997; Wang et al., 2001; Ding and Wang, 2005, 2007; Lin, 2009) and the Southern Hemisphere (SH) (Wang et al., 2001; Lin, 2009; Lee et al., 2013; Liu and Wang, 2013; Zhao et al., 2019). Several summer teleconnection patterns in the $\mathrm{NH}$ associated with tropical monsoons have been investigated, including the Pacific-Japan pattern (Nitta, 1987, 1989), the East AsiaPacific pattern (Huang and Lu, 1987, Huang and Sun, 1992), the circumglobal teleconnection pattern (Ding and Wang, 2005; Ding et al., 2011), the "silk road" pattern in the $200 \mathrm{hPa}$ meridional velocity (Lu et al., 2002; Enomoto et al., 2003), the Indo-Asian-Pacific pattern (Li et al., 2011; Li et al., 2013), and the North Atlantic- 
Eurasian teleconnection (Li et al., 2013; Li and Ruan, 2018; Li et al., 2019). In addition, the circulation variability in the $\mathrm{SH}$ induced by tropical heating was the topic of several studies, including the Pacific-South America pattern (Karoly, 1989), the South Africa-midlatitude pattern and the Maritime Continent-subtropical Australian pattern (Zhao et al., 2019). The mechanism proposed for these tropical-extratropical teleconnections is Rossby wave propagation and energy dispersion from localized tropical heating anomalies (Hoskins and Karoly, 1981; Branstator, 1983; Li and Nathan, 1994). As some theoretical studies have proved (e.g., Hoskins and Karoly, 1981; Simmons, 1982; Branstator, 1983; Lau and Lim, 1984; Branstator, 1985), these anomalies excite stable two-dimensional Rossby waves, thereby dispersing energy to remote regions of the globe.

These wave energy dispersion pathways can be well represented by the "great circle" ray trajectory (Hoskins and Karoly, 1981). However, in models with a zonally varying or zonally symmetric basic flow, stationary waves can only propagate in the westerlies and cannot cross the critical latitude (i.e., the zero zonal wind speed line; Hoskins and Karoly, 1981; Branstator, 1983). As there is a strong easterly wind prevailing at upper levels of the atmosphere in the Indian monsoon region during boreal summer, the Rossby waves are evanescent and cannot propagate into the $\mathrm{SH}$ in these kinds of models. In reality, however, the Asian monsoon system has a strong meridional circulation and its meridional wind cannot be neglected, compared with the zonal wind. Schneider and Watterson (1984) and Zhang et al. (1996) proved theoretically and numerically that the Hadley circulation allows Rossby waves to propagate from one 
hemisphere to another via the easterly winds.

$\mathrm{Li}$ and $\mathrm{Li}$ (2012) further considered the barotropic, non-divergent vorticity equation in a horizontally nonuniform basic flow, and found that steady Rossby waves can propagate in the easterlies when supported by the meridional wind. On the basis of the theory of $\mathrm{Li}$ and $\mathrm{Li}$ (2012), further research has also demonstrated that stationary waves originating from the tropical easterlies can propagate across the equator ( $\mathrm{Li}$ et al., 2015; Zhao et al., 2015, 2019).

Another physical mechanism behind cross-equatorial easterly teleconnections was proposed by Sardeshmukh and Hoskins (1988). They suggested that the equatorial forcing in the easterly winds induces a Rossby wave source in the subtropical westerlies caused by the advection of vorticity by the perturbed divergent flow. However, the divergent wind is much evident over upper tropospheric maritime continent during boreal summer and cannot simply explain the dynamical process of interhemispheric teleconnections associated with ISMR. In this study, therefore, stationary Rossby wave ray tracing is employed to investigate rainfall teleconnections simulated in the UM models.

The main focus of this study is to examine how the improved simulation of ISMR in GA7 compared with GA6 influences extratropical precipitation over the AustralianAsian monsoon region, and the nature of the underlying physical and dynamical mechanisms. We pay particular attention to exploring the signature of stationary Rossby wave energy dispersion in a horizontally nonuniform basic flow within the simulations. The paper is organized as follows. In Section 2, the model, data, and methodology 
used in this study are introduced. Section 3 is used to assess the rainfall simulations in GA6 and GA7. Section 4 describes the circulation anomalies in the $\mathrm{SH}$ and $\mathrm{NH}$ associated with ISMR and analyzes their influence on the extratropical rainfall. Section 5 presents the trajectories obtained via Rossby wave ray tracing and discusses the role of meridional wind ducts related to ISMR and South Asian High (SAH). Section 6 contains a summary and discussion.

\section{Model, data and methodology}

\subsection{Model}

In this paper, we use monthly precipitation, winds, and geopotential height data obtained from numerical experiments with the UM GA6 and GA7 (Walters et al., 2017, 2019) using a horizontal resolution of $60 \mathrm{~km}$ (N216 grid). We used atmosphere-only UM GA simulations by forcing the model with daily observed sea surface temperature (SST) and sea-ice conditions for the period 1982-2008, as in Walters et al. $(2017,2019)$ and Jin et al. (2019).

Detailed descriptions of the UM GA6 and GA7 configurations have been provided in several publications (Walters et al., 2017, 2019; Jin et al., 2019), and here we list only some of the key features that are relevant to this study. The GA6 solves the nonhydrostatic, fully compressible, deep-atmosphere equations of motion with a semiimplicit semi-Lagrangian formulation and ENDGame dynamical core (Wood et al., 2014). It uses extensively modified microphysics based on Wilson and Ballard (1999) and a revised version of the convection scheme of Gregory and Rowntree (1990) that includes downdrafts (Gregory and Allen, 1991) and convective momentum transport. 
As pointed out by Walter et al. (2019) and Jin et al. (2019), GA7 includes further developments of the model's microphysics scheme and incremental improvements to the implementation of the dynamical core. It includes improved treatment of gaseous absorption in the radiation scheme, improvements to the treatment of warm rain and ice clouds, and revisions to the model's convection scheme to improve the fidelity of the simulation of rainfall. These developments lead to large reductions in four critical model errors: rainfall deficits over India during the South Asian monsoon, temperature and humidity biases in the tropical tropopause layer, deficiencies in the model's numerical conservation, and surface flux biases over the Southern Ocean (Walters et al., 2019).

\subsection{Observational data}

In order to evaluate the simulated Indian Monsoon precipitation, we use monthly precipitation from the Global Precipitation Climatology Project (GPCP; Adler et al., 2003) for the period 1982-2008. Furthermore, the horizontal winds from ERA-Interim reanalysis (Dee et al., 2011) are used for the Rossby wave ray tracing, whilst the geopotential height from ERA-Interim reanalysis data with a resolution of $2.5^{\circ}$ longitude by $2.5^{\circ}$ latitude for the period $1982-2008$ is used to evaluate the monsoon circulation.

The indices used in this study are as follows. The Niño-3.4 index obtained from the Climate Prediction Center (http://www.cpc.ncep.noaa.gov/data/indices/), defined as the area-averaged SST anomalies over $5^{\circ} \mathrm{S}-5^{\circ} \mathrm{N}, 170^{\circ}-120^{\circ} \mathrm{W}$, is used to quantify the El Niño Southern Oscillation (ENSO). The Indian Ocean Dipole (IOD) Mode index 
177

178

(DMI) obtained from National Oceanic and Atmospheric Administration (NOAA) (http://www.esrl.noaa.gov/psd/gcos_wgsp/Timeseries/DMI/) is defined as the difference in the SST anomaly between the tropical western Indian Ocean $\left(10^{\circ} \mathrm{S}-10^{\circ} \mathrm{N}\right.$, $\left.50^{\circ}-70^{\circ} \mathrm{E}\right)$ and the southeastern Indian Ocean $\left(10^{\circ} \mathrm{S}-0^{\circ} \mathrm{N}, 90^{\circ}-110^{\circ} \mathrm{E}\right.$; Saji et al., 1999$)$. To quantify the Indian summer monsoon, many indices based on the precipitation, OLR or $850 \mathrm{hPa}$ wind anomalies have been used in the literature (Wang et al., 2001; Li and Zeng, 2002, 2003, 2005; Ding and Wang, 2007). In this paper, in order to evaluate the ISMR-dependent teleconnections in GA6 and GA7, we define the ISMR Index (ISMRI) as the normalized area-averaged rainfall anomaly over the Indian subcontinent $\left(5^{\circ}-\right.$ $25^{\circ} \mathrm{N}, 70^{\circ}-90^{\circ} \mathrm{E}$ ), as in Jin et al. (2019). Furthermore, we define the ISMR as being strong (weak) when the ISMRI is above (below) $0.75(-0.75)$ considering both the significance and the number of strong (weak) ISMR events. Furthermore, both the strong and weak ISMR years selected in observation and GA7 are six years, and the strong and weak ISMR years in GA6 are seven and six years, respectively. Note that by choosing a larger domain covering the whole of the south Asian monsoon region, Jin et al. (2019) showed that the agreement between GA7 simulations and observations was much improved. We define the south Asian monsoon region as the area over $5^{\circ}-25^{\circ} \mathrm{N}$, $30^{\circ}-90^{\circ} \mathrm{E}$.

\subsection{Partial correlation}

In our analysis, we use the first-order partial correlation coefficient (Anderson, 1984) to calculate the correlation between two time series, excluding the effect of one other control variable as follows: 


$$
r_{i j \cdot k}=\frac{r_{i j}-r_{i k} \times r_{j k}}{\sqrt{\left(1-r_{i k}^{2}\right) \times\left(1-r_{j k}^{2}\right)}},
$$

where $r_{i j \cdot k}$ denotes the partial correlation of variables $i$ and $j$, excluding the effect of $k, r_{i j}$ refers to the linear correlation between variables $i$ and $j, r_{i k}$ refers to the linear correlation between variables $i$ and $k$, and $r_{j k}$ refers to the linear correlation between variables $j$ and $k$.

The second-order partial correlation coefficient (Anderson, 1984), used to determine the correlation between two time series excluding the effect of two other control variables, is calculated as follows:

$$
r_{i j \cdot k h}=\frac{r_{i j \cdot k}-r_{i h \cdot k} \times r_{j h \cdot k}}{\sqrt{\left(1-r_{i h \cdot k}^{2}\right) \times\left(1-r_{j h \cdot k}^{2}\right)}}
$$

where $r_{i j \cdot k h}$ denotes the partial correlation between variables $i$ and $j$, excluding the signals of $k$ and $h$, and $r_{i j \cdot k}, r_{i h \cdot k}$, and $r_{j h \cdot k}$ can be obtained from Eq. (1).

\subsection{Partial regression}

The partial regression is adopted to estimate how much of the variation of the response variable can be attributed exclusively to one set of factors, once the effect of the other set has been taken into account and controlled for. Specifically, the influences of the considered factors on the studied variables are eliminated the step by step. Let's take three independent variables $\mathrm{X}, \mathrm{X} 1, \mathrm{X} 2$ as an example, and $\mathrm{Y}$ be the dependent variable. Firstly, the effect of $\mathrm{X} 1$ on $\mathrm{y}$ is removed by subtracting the regression of $\mathrm{Y}$ on $\mathrm{X} 1$. The regressed values of $\mathrm{Y}$ are assumed to follow certain distribution: 


$$
\widetilde{Y}^{\prime}(t)=a X 1^{\prime}(t)+a 1
$$

219 primes represent departure from the mean state, a is the regression coefficient, and $a 1$ is the intercept of linear regression. $\widetilde{Y^{\prime}}$ indicates the linear contribution of $X 1^{\prime}$ on $Y^{\prime}$. Then the effect of $X 1$ on $Y$ is eliminated by

$$
Y^{\prime *}(t)=Y^{\prime}(t)-\widetilde{Y^{\prime}}(t)
$$

$Y^{\prime *}$ is isolate from $X 1$. Then the same way is used to remove the liner influence of $X 2$ on y. Linear contribution of $X 2$ on $Y^{\prime *}$ is

$$
\widetilde{Y^{\prime *}}(t)=b X 2^{\prime}(t)+b 1
$$

where $\widetilde{Y^{\prime *}}$ indicates the regression of $Y^{\prime *}$ on $X 2^{\prime}$. The linear influence of $X 2$ can be excluded by

$$
Y^{\prime * *}(t)=Y^{\prime *}(t)-\widetilde{Y^{\prime *}}(t)
$$

229 In this case, the linear contributions of $X 1$ and $X 2$ on $Y^{\prime}(t)$ are removed. The $\widetilde{Y^{\prime * *}}(t)$ that is attributed exclusively to $X$ takes the form of

$$
\widetilde{Y^{* * *}}(t)=c X^{\prime}(t)+c 1
$$

in which $c$ is the partial regression coefficient, and $\widetilde{Y^{\prime * *}}$ is the partial regressed value by $X^{\prime}$.

\subsection{Rossby wave theory in a nonuniform horizontal basic flow}

Rossby wave ray tracing theory describes the pathway of wave energy dispersion (Hoskins and Karoly, 1981, Li et al., 2015; Zhao et al., 2015, 2019) and has been widely used to explore atmospheric teleconnections. Thus, it is used in this study to reveal the dynamical link between ISMR and the extratropical climate. A linearized, spherical barotropic Rossby wave ray tracing model proposed by Li and Li (2012) and Li et al. 
240

241

242

243

244

245

(2015) is employed to study steady, linear Rossby wave patterns in a nonuniform horizontal basic flow. According to Zhao et al. $(2015,2019)$, the dispersion relation of a barotropic Rossby wave is

$$
\omega=\bar{u}_{M} k+\bar{v}_{M} k+\frac{l \partial \bar{q} / \partial x-k \partial \bar{q} / \partial y}{K^{2}},
$$

where $\omega$ is the frequency, $\left(\bar{u}_{M}, \bar{v}_{M}\right)=(\bar{u}, \bar{v}) / \cos \varphi$ is the Mercator projection of the basic-state zonal and meridional winds, $\varphi$ is the latitude, $q=2 \Omega \sin \varphi+\nabla^{2} \bar{\psi}$ is the basic-state absolute vorticity, $\Omega$ is the rotation rate of Earth, $\bar{\Psi}$ is the basic-state stream function, $K=\sqrt{k^{2}+l^{2}}$ is the total wavenumber, and $k$ and $l$ are the zonal and meridional wavenumbers, respectively. The local group velocity $\boldsymbol{C}_{g}=\left(u_{g}, v_{g}\right)$ obtained from Eq. (8) takes the form (Li et al., 2015; Zhao et al., 2015)

$$
\begin{gathered}
u_{g}=\bar{u}_{M}+\left[\left(k^{2}-l^{2}\right) \partial \bar{q} / \partial y-2 k l \partial \bar{q} / \partial x\right] / K^{4} \\
v_{g}=\bar{v}_{M}+\left[2 k l \partial \bar{q} / \partial y+\left(k^{2}-l^{2}\right) \partial \bar{q} / \partial x\right] / K^{4}
\end{gathered}
$$

The wave ray trajectory is tangential to the group velocity (Lighthill, 1978). The wavenumbers $k$ and $l$, which are determined by kinematic wave theory (Whitham, 1960; Shaman et al., 2012), vary with the position of the ray,

$$
\begin{gathered}
\frac{d_{g} k}{d t}=-k \frac{\partial \bar{u}_{M}}{\partial x}-l \frac{\partial \bar{v}_{M}}{\partial x}+\frac{k \partial^{2} \bar{q} / \partial y \partial x-k \partial^{2} \bar{q} / \partial x^{2}}{K^{2}}, \\
\frac{d_{g} l}{d t}=-k \frac{\partial \bar{u}_{M}}{\partial y}-l \frac{\partial \bar{v}_{M}}{\partial y}+\frac{k \partial^{2} \bar{q} / \partial y^{2}-k \partial^{2} \bar{q} / \partial x \partial y}{K^{2}},
\end{gathered}
$$

where $d_{g} / d t=\partial / \partial t+C_{g} \cdot \nabla$. For stationary waves $(\omega=0)$, the initial local meridional wavenumber $l$ is determined from the dispersion relation Eq. (8) for each initial zonal wavenumber $k$ and a given starting point. Then, the ray trajectory can be numerically integrated from Eqs (9) and (10). The integration was aborted when the local meridional wavelength was calculated as $<1000 \mathrm{~km}$. 

energy is dominated by the basic zonal flow, basic meridional flow, and absolute vorticity gradient. Notably, the meridional basic flow plays an important role in the dispersion of wave energy particularly over tropical monsoon region where meridional wind can't be ignored compared with zonal wind. Furthermore, considering the wave ray trajectory is sensitive to the background flow and the atmospheric circulation is subject to multiple factors, it is necessary to extract the influence of heating anomalies on the background flow by partial regression. In this paper, we considered the effects of ENSO and IOD. The basic flow is divided into climatological and abnormal parts, and abnormal wind is partial regressed onto the ISMRI to exclude the effects of ENSO and IOD.

\section{Rainfall simulations in GA6 and GA7}

Many studies have reported that the tropical monsoons have consequences for rainfall outside the tropics (Nitta, 1987; Hoskins and Rodwell, 1995; Rodwell and teleconnections. In the study of Jin et al. (2019), they eliminated the effect of ENSO 
the Australian-Asian monsoon region in GA6 and GA7. Although they discussed the likely influence of the IOD on rainfall anomalies in the Australian-Asian region (Ashok et al., 2001; Zhao et al., 2014; Zhao and Zhang, 2016) in GA6 and GA7, their analysis did not remove the effects of the IOD. In this study, we take both the IOD and ENSO into account.

Figure 1 displays the correlations and partial correlations between the ISMRI and the June-July-August (JJA) rainfall over the Australian-Asian monsoon region from GPCP, GA6, and GA7, excluding the impacts of the IOD and ENSO. The partial correlations bare close resemblance to the full correlations. Notably, the rainfall anomalies in the SH particularly over southwest Australia are more evident in GPCP after removing the impacts of ENSO and IOD indicating that the influence of ENSO, IOD and ISMR on the SH rainfall teleconnections are relatively depended. Furthermore, the rainfall teleconnections are in good agreement with the results of Jin et al. (2019; cf. their Fig. 7). In the NH, a wave train-like rainfall teleconnection pattern (Wu, 2002, 2017; Kim et al., 2002), which shows positive correlations over Arabian Peninsula, Northern China and Mongolia, and negative correlations over Central Asia and the Korean Peninsula, is much better captured by GA7 (Figs. 1a, b, c), as reported in Jin et al. (2019, cf. their Fig. 7). In addition, in the NH, the anomalous rainfall pattern correlations between GA7 and observations for the full correlation and partial correlation are 0.496 and 0.431 , respectively, but is better than GA6, where the correlation with observations are 0.329 and 0.255 , respectively. 
correlations over tropical western Indian Ocean and southwest Australia and the nearby

Indian Ocean (Figs. 1a, d), are evident in observations, as also shown by Jin et al. (2019, cf. their Fig. 7). The anomalous rainfall pattern correlation in the SH between GA7 and observations for the full correlation and partial correlation are 0.251 and 0.068 . respectively, but is better and worse simulated in GA6, where the correlations with observations are 0.155 and 0.26 , respectively. The decrease in the partial correlation between GA7 and observations is mainly owning to the different influences of ENSO and IOD on the rainfall teleconnection magnitude in GA7 and observation. However, according to the full correlation, the wave-train-like correlation pattern is still better captured by GA7 (Figs.1b, c, d, e). Particularly, GA6 overestimated the positive correlation over Australia and the overestimation is reduced in GA7 (Figs.1b, c, d, e). Overall, the rainfall correlation between GA7 and observations over the AustralianAsian domain $\left(50^{\circ} \mathrm{S}-60^{\circ} \mathrm{N}, 30^{\circ}-180^{\circ} \mathrm{E}\right)$ is still low at 0.31 , but is better than GA6, where the correlation with observations is 0.251. In addition, the rainfall teleconnections in the $\mathrm{NH}$ are better simulated than that in the $\mathrm{SH}$ for both GA6 and GA7. Moreover, we still have to point out that the rainfall correlations with the ISMRI over ISM and northwest of ISM regions are poor simulated in both GA6 and GA7 which need further investigation.

We further evaluate the ISMR intensity to help understand the fidelity of rainfall teleconnections simulated in GA6 and GA7. Figure 2 shows the spatial distribution of precipitation during years of strong and weak ISMR in observations, GA7, and GA6. 
Rainfall deficits over the Indian subcontinent during years of strong ISMR are reduced markedly in GA7 simulations. This is accompanied by a much smaller rainfall overestimation in the tropical Indian Ocean in GA7 compared with GA6. Such results are consistent with the findings from Bush et al. (2015) and Willetts et al. (2017), which suggested that excessive rain over the equatorial Indian Ocean warm waters might have contributed to the lack of Indian monsoon rainfall. Our analysis further shows that this may be particularly true in strong monsoon years (Fig. 2h). Similarly, the opposite situation occurred over East Asia and the nearby Philippines Sea. The rainfall over the nearby Philippian Sea and East Asia are worse overestimated and underestimated in GA7 than that in GA6 particularly during the years of strong ISMR (Fig. 2h). Thus, poor rainfall simulation in GA7 over East Asian monsoon region is also a concern for model improvement.

Overall, the rainfall pattern correlations between GA7 (GA6) and observation during years of strong and weak ISMR are $0.875(0.811)$ and $0.800(0.748)$ over the lower latitude of Australian-Asian domain $\left(30^{\circ} \mathrm{S}-40^{\circ} \mathrm{N}, 30^{\circ}-180^{\circ} \mathrm{E}\right)$. Thus, the rainfall simulation is improved in GA7 compared with GA6. Furthermore, the differences between GA7 and GA6 over the Indian monsoon domain in years of strong ISMR are much more significant than in years of weak ISMR (Figs. $2 g, h$ ). These improved rainfall simulations in GA7 during strong ISMR years may help to better understand the link between the improved ISMR and the more realistically simulated rainfall teleconnections in GA7. 


\section{Circulation anomalies}

Circulation anomalies associated with the ISMR are analyzed using regression and partial regression of stream function and wind anomalies at $500 \mathrm{hPa}$ onto the ISMRI (Figure. 3). As shown in Fig. 3, two distinct barotropical wave trains originated from the ISM region propagating northward and southward into the $\mathrm{NH}$ and $\mathrm{SH}$ subtropics are observed in observations. In the $\mathrm{NH}$, the full regressed circulation pattern resembles the circumglobal teleconnection (Ding and Wang 2005). The magnitude of the circumglobal teleconnection decreases sharply and only three centers are observed over Eurasia after removing the signals of ENSO and IOD (Fig. 3d). In the SH, the atmospheric responses also become weaker after removing the signals (Fig. 3d) suggesting the dependent influences of ENSO, IOD and ISMR on the circulation.

Originated from the ISM region, the wave train first propagates westward to the Arabian Peninsula creating a region of abnormally cyclonic circulation, then northeastward to Central Asia, creating a region of abnormally anti-cyclonic circulation, and then eastward to Mongolia and northern China, creating a region of abnormally cyclonic circulation, and finally eastward to the northeast China and Korean Peninsula, creating a region of abnormally anti-cyclonic circulation (Fig.3d). In the SH, the wave train first propagates southwestward to tropical western Indian Ocean creating a region of abnormally anti-cyclonic circulation, then southward across Indian Ocean creating a region of abnormally cyclonic circulation over the subtropical Indian Ocean and anticyclonic circulation over mid-latitude Indian Ocean and southwestern Australia (Fig. 3d). This is consistent with the investigation by Zhao et al. (2019), who noted that an 
equivalent barotropic wave train originating from the Maritime Continent propagates southward to subtropical Australia. The two tropical cyclonic circulations over Arabian Peninsula and tropical western Indian Ocean excited by ISMR resemble the opposite signs of Gill-type responses to tropical diabatic heating (Gill 1980) as discussed in Jin et al. (2019, cf. their Fig. 10). The atmospheric response patterns over Australia-Asia monsoon region are observed in GA7, whereas the anomalous anti-cyclonic circulations over Central Asia and subtropical Indian Ocean are not captured by GA6. Furthermore, the abnormally cyclonic circulation over midlatitude Indian Ocean is underestimated in GA6.

Figure 4 shows a map of partial regression of vertical velocity and geopotential height anomalies at $500 \mathrm{hPa}$ onto the ISMRI removing the signals of ENSO and IOD. In the regions downstream of the troughs (cyclones) ascending anomalies are observed, while in the regions downstream of the ridges (anti-cyclones) subsidence anomalies are observed (Fig. 4). This vertical motions correspond to the westward tilt structure of the extratropical atmosphere. The anomalous vertical velocity pattern associated with the ISMR bears a strong resemblance to the rainfall pattern shown in Fig. 1. In particular, the anomalous subsidence motions over Central Asia and Japanese islands which are not conducive to the formation of precipitation are better simulated in GA7 than that in GA6 (Figs. 4b, c). The subsidence anomaly over equatorial Indian Ocean and ascending anomaly over central Australia are overestimated in GA6 but significantly improved in GA7 (Figs. 4b, c). In addition, the vertical motion is opposite in the south and north ISM region, which is not well simulated in both GA6 and GA7 (Figs. 4b, c). 
moisture source associated with the ISMR. Figure 5 shows the partial correlation between moist flux transports at $850 \mathrm{hPa}$ and ISMR in observation and GA7, GA6 excluding the effects of ENSO and IOD. The anomalous moisture transports are close to the circulation anomalies in Figure 3 indicating the important role of advection in the moisture transports associated with the ISMR. As shown in Figure 5, the northward anomalous moisture flux transports over East Asia and anti-cyclonic moisture flux transports over subtropical Indian Ocean are better simulated in GA7 contributing to the precipitation increase over northern China and southwest Australia respectively. Particularly, the moisture transports are underestimated over subtropical Indian Ocean and overestimated over central Australia in GA6 which is corresponded to the rainfall anomalies (Fig. 5c). Overall, the influences of ISMR-teleconnection on the vertical motions and moisture transports lead to the formation of rainfall teleconnection. Therefore, the better simulated ISMR-teleconnection helps to improve the presentation of extratropical rainfall in the models.

\section{Rossby wave ray tracing and the role of the meridional basic flow}

Rossby wave ray tracing in a horizontally non-uniform flow, which describes the pathways of Rossby wave dispersion, is adopted to investigate the link between the improved ISMR and the associated rainfall teleconnections. Technical details about the wave ray tracing analysis can be found in Zhao et al. (2015, 2019). Before describing the wave ray, the background flow is analyzed. Figure 6 shows the composite difference 
in full regressed and partial regressed wind anomalies at $250 \mathrm{hPa}$ between strong and weak ISMR years. The partial regressed anomalous winds are similar to that full regressed, but with slight changes in the magnitude of wind anomalies in GA7 and observation suggesting the independent influences of ENSO, IOD and ISMR on the upper tropospheric wind in observation and GA7. As shown in Fig6., the anti-cyclonic circulations over Central Asia and East Asia and a cyclonic circulation over subtropical Indian Ocean (Fig. 6) are in good agreement with the results of Wang et al. (2001, cf. their Fig. 8). Particularly, this anomalous circulation pattern is close to the circulation pattern at $500 \mathrm{hPa}$ associated with the ISMR (Figs. 3e, f) indicating that the response of the extratropical atmosphere to the ISMR is quasi-barotropical. The background flow used to calculate the stationary wave ray trajectories is the superposition of the composite of partial regressed anomalous wind and the climatology wind.

\subsection{Rossby wave ray tracing}

Figure 7 illustrates the stationary wave ray trajectories of zonal wavenumbers $2-5$ emanating from ISMR sources in observations, GA7, and GA6. The wave rays first propagate westward to tropical Africa, then divide to propagate to the $\mathrm{NH}$ and $\mathrm{SH}$ subtropics (Fig. 7). Evidently, the southern branch of the wave rays in years of strong ISMR is more evident than that in years of weak ISMR, indicating the likely diabatic heating influence of ISMR on the cross equatorial Rossby wave propagation. Furthermore, the wave rays in the $\mathrm{SH}$ subtropics are much more than those in the NH in observations (Figs. 7a, b, c), leading to stronger wave trains in the SH (Figs. 3a, b). 
This is better captured by GA7 during years of strong ISMR (Fig. 7e) than GA6 (Fig. 7h). On the other hand, both GA6 and GA7 simulate weaker wave propagation in the SH than that observed in years of weak ISMR (Figs. 7f, i), although in GA7, the propagation towards tropical Africa is somewhat closer to observations (Fig. 7f).

The situation is similar for the northern branch of wave rays. The northern waveray characteristics simulated in GA7 in years of strong ISMR are much closer to observations than in GA6, with wave rays occurring in the subtropical westerlies over Asia (Figs. 7b, e). However, during years of weak ISMR, the northern branch of the wave rays in both GA7 and GA6 are poorly simulated (Figs. 7f, i), with wave rays being much stronger and further poleward than in observations. Both GA6 and GA7 perform poorly in reproducing the observed characteristics of wave rays in weak ISMR years, during which both model configurations showed a significant dry bias over the Indian monsoon domain in JJA (Fig. 2). Nevertheless, it is not clear whether we can directly associate the poor simulation of wave rays with the underestimation of ISMR.

This is because during weak ISMR years, one would expect weak diabatic heating over the Indian monsoon region. However, without considering the diabatic influence of deep monsoon convection on the mean flow, the increase of isolated equatorially asymmetric heating only strengthens the atmospheric response, but not vary the atmospheric patterns (Xing et al., 2014). We need to investigate further to what extent the model's failure to reproduce wave propagation in weak monsoon years is because of the poor simulation of the atmospheric mean flow in the region, or because of the significant lack of rainfall during those years. 


\subsection{Meridional wind ducts in the upper troposphere}

According to the studies by Zhao et al. $(2015,2019)$ and Li et al. (2015), the meridional basic flow plays an important role in facilitating the propagation of stationary Rossby wave. Furthermore, the interhemispheric propagation of Rossby waves is dominated largely by the meridional flow (Lee et al., 2013; Liu and Wang, 2013; Li et al., 2015; Zhao et al., 2015, 2019). Figure 7 shows the $250 \mathrm{hPa}$ horizontal winds from ERA-interim, GA7, and GA6 in JJA. As shown in Fig. 7a, strong easterly winds prevail at upper levels over the tropical Australian-Asian and African monsoon regions. In tropical North Africa, southerly winds prevail between $10^{\circ} \mathrm{N}$ and $30^{\circ} \mathrm{N}$, whilst northerly winds prevail below $10^{\circ} \mathrm{N}$, causing the Rossby wave to first propagate westward and then divide northward and southward over tropical North Africa and beyond. Similarly, the northerly winds over the Indian subcontinent and tropical Indian Ocean also lead the Rossby wave to propagate southward into the SH. The southerly winds prevailing over the western Tibetan Plateau drive the Rossby wave northward into the Asian subtropical westerlies.

The poor simulated meridional propagation of Rossby wave is closely related to the modelling errors of the meridional wind. The significantly weak simulated northerly winds over the upper tropospheric South Asian monsoon domain in GA6 (Figs. 8e, f) are not favorable to the cross-equatorial propagation of Rossby wave. Furthermore, the strength of the simulated meridional winds in Asia in GA6 are stronger than that shown in observations (Figs. 8e, f), especially for the southerly winds over the western Tibetan Plateau. This contributes to the stronger and further poleward propagation of Rossby 
477

478

479

480

481

482

483

484

485

486

487

488

489

490

491

492

493

494

495

496

497

498

wave in GA6 (Figs. 7g, h, i). In contrast, the upper tropospheric meridional winds over the western Tibetan Plateau and south Asian monsoon are more realistically simulated in GA7 (Fig. 8d), especially in years of strong ISMR (Fig. 8h). Therefore, analyzing to what extend the simulation of ISMR influence the meridional wind will help to understand the contribution of improvement of ISMR to the Rossby wave propagation. Furthermore, as discussed by Jin et al. (2019) the SAH is closely linked to the diabatic heating effect of the tropical Indian monsoon, the influence of SAH on the meridional wind will also be considered.

The strength of SAH is defined as the averaged geopotential height of grid within the isoline of $12500 \mathrm{gpm}$ at $200 \mathrm{hPa}$ (Figures $9 \mathrm{~g}, \mathrm{~h}, \mathrm{i}$ ). The multiple regression is used to measure the liner contributions of ISMR and SAH to the meridional wind. Considering the relationship between SAH and ISMR, we removed the linear effect of SAH on ISMR through partial regression. Fig. 9 shows the climatology of SAH and the multiple regression of meridional wind on the ISMRI and SAHI. As shown in Fig. 9, the meridional winds over South Asian monsoon region in GA6 and GA7 is closely related to ISMR. With the increase of ISMR, stronger convective activity enhances the Indian monsoon circulation, the upper northerly wind over South Asian monsoon region enhances (Fig. 8h), making stronger cross equatorial Rossby wave (Fig. 7e). Furthermore, the relationship between anomalous northerly wind over western Tibetan Plateau and ISMR is better simulated in GA7 than that in GA6 (Figs. 9b, c). Moreover, the contribution of SAH to the upper meridional wind over South Asian monsoon region in GA7 are better simulated than that in GA6 (Figs. 9e, f). Therefore, both the 
enhancement of ISMR and SAH during years of strong ISMR in GA7 contribute to the more realistic meridional wind over south Asian monsoon and western Tibetan Plateau, and hence make more realistic propagation of Rossby wave.

What's more, the simulation of SAH in GA7 is improved significantly compared with that in GA6. Due to the dynamic relationship between wind and pressure, the simulation of wind improves with the improvement of pressure. Particularly, at midlatitudes, the pressure dominates the wind according to the geostrophic relationship. As a result, the improvement of SAH in GA7 leads to more realistic climatic mean flow over South Asia than that in GA6 (Figs. 9g, h, i). In particular, the much stronger southerly wind over western Tibetan Plateau and south Asian monsoon region in GA6 is mainly owning to the poor simulation of SAH (Fig. 9i). Furthermore, the improvement of ISMR intensity with more realistic convective heating in GA7 contributes to more realistic meridional wind over South Asian monsoon region.

Nevertheless, it still has to point out that the inter-annual variability of ISMR in GA7 needs to be improved, and the relationship between SAH and ISMR is overestimated in GA6 and GA7 with the correlation coefficients of 0.48 and 0.33 , respectively, while 0.13 in the observation. The significant improvement of SAH in GA7 corresponds to the skillfully simulated ISMR, which may own to the deeper convection and more realistic diabetic heating are allowed in GA7 (Walters et al. 2019).

\section{Summary and discussion}

In this study, we have investigated the link between the improved simulation of ISMR and the associated extratropical rainfall teleconnections in two versions of the 
521

522

523

524

525

526

527

UKMO Unified Model, GA6 and GA7, using Rossby wave ray tracing theory (Li and Li et al., 2012; Li et al., 2015; Zhao et al., 2015, 2019). In a previous UM assessment study, Jin et al. (2019) reported that the reduced Indian monsoon dry bias in UM GA7 at N216 resolution led to more realistic monsoon rainfall teleconnection patterns. However, they did not conduct detailed wave propagation analysis to support these results. Therefore, our study focused on investigating Rossby wave propagation in these two model configurations by using Rossby wave ray tracing in a horizontally nonuniform background flow, as in Zhao et al. $(2015,2019)$.

Our observational analysis showed that the diabatic heating associated with ISMR can excite two distinct wave trains in the $\mathrm{NH}$ and $\mathrm{SH}$ subtropics. GA7 can better simulate the teleconnections associated with the ISMR over Australia-Asia monsoon region compared with GA6. The realistic simulated atmospheric teleconnection in GA7 plays an important role in the improvement of rainfall teleconnection by modulating the vertical motion and the moisture transport.

The teleconnection wave train coincides with the pathway of the stationary Rossby wave propagation. Driven by the upper tropospheric easterly flow, the stationary Rossby wave first propagate westward, then separate into northern and southern branches following the meridional wind ducts. The northern branch mainly propagates in the subtropical westerlies over Asia and the southern branch primarily propagates in the SH subtropical westerlies. Compared with GA6, GA7 can better capture the characteristics of Rossby wave propagation pathways in years of strong ISMR, with stronger cross-equatorial propagation and a more realistic northern branch 
of the wave ray tracing trajectories. This was attributed largely to the model skillfully simulating of ISMR and SAH, and their influences on the meridional basic flow over upper South Asia monsoon and western Tibetan Plateau.

Our study may also provide new insights for monsoon teleconnection evaluations by revealing the Rossby wave propagation pathway from the upper tropospheric easterlies. The upper tropospheric meridional winds associated with the monsoon system play an important role in Rossby wave propagation and hence improve the simulation of tropical monsoon teleconnections. Sakaguchi et al. (2016) detected changes in Rossby wave ray trajectories influenced by Asian monsoon rainfall and the associated basic flow using different grid refinements in the Community Atmosphere Model version 4. The teleconnection pathways revealed by Rossby wave ray trajectories provide implications for evaluating and improving the model's performance of simulating tropical monsoon teleconnections.

The analysis in this paper was focused mainly on the Australian-Asian monsoon region, but further research could be done to evaluate the influence of the tropical Asian monsoon on the weather and climate over other regions. It is also worth noting that significant deficiencies in the modelling of ISMR remain, despite the reduced dry bias in GA7. In particular, the northerly wind ducts over the upper tropospheric South Asian monsoon region in GA7 are poorly simulated. Walter et al. (2019) indicated that the southern branch of the Hadley circulation during JJA in GA7 using an N216 grid was improved significantly compared with GA6 at the same resolution, due to the deeper convection in GA7. Thus, the simulation of convection is important to improve the 
572 simulated by current CMIP models.

\section{Acknowledgements}

575 This work was jointly supported by the National Natural Science Foundation of China (NSFC,

57641530424 and 41790474) projects, Shandong Natural Science Foundation Project

577 (ZR2019ZD12) and Fundamental Research Funds for the Central Universities (201962009).

578 HZ acknowledges the UM partnership for making the model simulations available and 579 supporting this study. HZ and JL appreciate the discussions with scientists at the UM Global 580 Teleconnection Workshop, Met Office, UK 17-26 June 2019. 


\section{References}

583

584

585

586

587

588

589

590

591

592

593

594

595

596

597

598

599

600

601

602

603

604

605

606

607

608

609

610

Adler RF et al (2003) The version 2 Global Precipitation Climatology Project (GPCP) monthly precipitation analysis (1979-present). J Hydrometeorol 4:1147-1167

Anand A, Mishra, SK, Sahany S, Bhowmick M, Rawat JS, Dash SK (2018) Indian summer monsoon simulations: usefulness of increasing horizontal resolution, manual tuning, and semi-automatic tuning in reducing present-day model biases. Sci Reports 8(1):3522

Anderson TW (1984) An Introduction to Multivariate Statistical Analysis, 2nd edn. Wiley, New York, pp 675

Ashok K, Guan Z, Yamagata T (2001) Impact of the Indian Ocean Dipole on the relationship between the Indian monsoon rainfall and ENSO. Geophys Res Lett 28:4499-4502

Branstator G (1983) Horizontal energy propagation in a barotropic atmosphere with meridional and zonal structure. J Atmos Sci 40:1689-1708

Branstator G (1985) Analysis of general circulation model sea-surface temperature anomaly simulations using a linear model. Part I: Forced solutions. J Atmos Sci 42:2225-2241

Bush SJ, Turner AG, Woolnough SJ, Martin GM, Klingaman NP (2015) The effect of increased convective entrainment on Asian monsoon biases in the MetUM general circulation model. Q J R Meteorol Soc 141:311-326.

Ding Q, Wang B (2005) Circumglobal teleconnection in the Northern Hemisphere summer. J. Clim 18:3483-3505

Ding Q, Wang B (2007) Intraseasonal teleconnection between the summer Eurasian wave train and the Indian monsoon. J Clim 20:3751-3767

Ding Q, Wang B, Wallace JM, Branstator G (2011) Tropical-extratropical teleconnections in boreal summer: Observed interannual variability. J Clim 24:1878-1896. http://doi.org/10.1175/ 2011JCLI3621.1

Dee DP et al (2011) The ERA-Interim reanalysis: configuration and performance of the data assimilation system. Q J R Meteorol Soc 137:553-597 
Enomoto T, Hoskins BJ, Matsuda Y (2003) The formation mechanism of the Bonin high in August. Q J R Meteorol Soc 129:157-178. http://doi.org/10.1256/qj.01.211

Gill AE (1980) Some simple solutions for heat-induced tropical circulation. Q J R Meteorol Soc 106(449):447-462. https://doi.org/10.1002/qj.49710 644905

Gregory D, Rowntree PR (1990) A Mass Flux Convection Scheme with Representation of Cloud Ensemble Characteristics and Stability-Dependent Closure. Monthly Weather Review 118(7):1483-1506. https://doi.org/10.1175/15200493(1990)118<1483:AMFCSW>2.0.CO;2

Gregory D, Allen S (1991) The effect of convective scale downdraughts upon NWP and climate simulations. In: 9th conference on numerical weather prediction. Amer Meteorol Soc 122-123

Hirst A (2015) Towards CMIP6: plans for participation by ACCESS. In: CAWCR 9th annual workshop 19-22

Hoskins BJ, Rodwell MJ (1995) A model of the Asian summer monsoon. Part I: the global scale. J Atmos Sci 52:1329-1340

Hoskins BJ, Karoly DJ (1981) The steady linear response of a spherical atmosphere to thermal and orographic forcing. J Atmos Sci 38(6):1179-1196. https://doi.org/10.1175/1520-0469(1981)038<1179:TSLROA>2.0.CO;2

Hudson D et al (2017) ACCESS-S1: the new Bureau of Meteorology multi-week to seasonal prediction system. J South Hemisph Earth Syst Sci 67:132-159

Karoly DJ (1989) Southern Hemisphere Circulation Features Associated with El NiñoSouthern Oscillation Events. J Clim 2(11):1239-1252

Kim B-J, Moon S-E, Lu R, Kripalani RH (2002) Teleconnections: summer monsoon over Korea and India. Adv Atmos Sci 19:665-676

Kripalani RH, Kulkarni A, Singh SV (1997) Association of the Indian summer monsoon with the Northern Hemisphere mid-latitude circulation. Int J Climatol $17: 1055-1067$

Lau K-M, Lim H (1984) On the dynamics of equatorial forcing of climate teleconnections. J Atmos Sci 41:161-176 
Lee SK, Mechoso CR, Wang C, Neelin JD (2013) Interhemispheric influence of the northern summer monsoonson southern subtropical anticyclones. J Clim 26(24):10193-10204

Lee SK, Wang C, Mapes BE (2009) A simple atmospheric model of the local and teleconnection responses to tropical heating anomalies. J Clim 22(2):272-284. https://doi.org/10.1175/2008jcli2303.1

Li L, Nathan TR (1994) The global atmospheric response to low-frequency tropical forcing: Zonally averaged basic states. J Atmos Sci 51:3412-3426

Li JP, Zeng QC (2002) A unified monsoon index. Geophys Res Lett 29(8):115-1-1154

Li JP, Zeng QC (2003) A new monsoon index and the geographical distribution of the global monsoons. Adv Atmos Sci 20:299-02

Li JP, Zeng QC (2005) A new monsoon index, its interannual variability and relation with monsoon precipitation. Climatic Environ Res (in Chinese) 10(3):351-365

Li JP, Wu GX, Hu DX et al (2011) Ocean-Atmosphere Interaction over the Joining Area of Asia and Indian-Pacific Ocean and Its Impact on the Short-Term Climate Variation in China (Volume I). Beijing: China Meteorol Press 1-30

Li JP et al (2013) Progress in air-land-sea interactions in Asia and their role in global and Asian climate change (in Chinese). Chin J Atmos Sci 37:518-538

Li JP, Ruan CQ (2018) The North Atlantic-Eurasian teleconnection in summer and its effects on Eurasian climates. Environ Res Lett 13:024007. https://doi.org/10.1088/1748-9326/aa9d33

Li JP, Zheng F, Sun C, Feng J, Wang J (2019) Pathways of influence of the Northern Hemisphere mid-high latitudes on East Asian climate: A Review. Adv Atmos Sci 36:902-921

Li Y, Li JP (2012) Propagation of planetary waves in the horizontal non-uniform basic flow (in Chinese). Chin J Geophys 55(2):361-371. https://doi.org/10.6038/j/issn.0001-5733.2012.02.001

Li Y, Li JP, Feng J (2013) Boreal summer convection oscillation over the Indo-Western Pacific and its relationship with the East Asian summer monsoon. Atmos Sci Lett 


$$
\text { 14(2):66-71 }
$$

Li Y, Li JP, Jin FF, Zhao S (2015) Interhemispheric propagation of stationary Rossby waves in the horizontally nonuniform background flow. J Atmos Sci 72(8):32333256. https://doi.org/10.1175/JAS-D-14-0239.1

Lighthill J (1978) Waves in Fluids. Cambridge University Press, pp 540

Lin, H (2009) Global extratropical response to diabatic heating variability of the Asian summer monsoon. J Atmos Sci 66:2697-2713

Liu F, Wang B (2013) Mechanisms of global teleconnections associated with the Asian summer monsoon: An intermediate model analysis. J Clim 26:1791-1806. http://doi.org/10.1175/JCLI-D-12-00243.1

Lu R, Oh J-H, Kim B-J (2002) A teleconnection pattern in upper-level meridional wind over the North African and Eurasian continent in summer. Tellus 54A:44-55, http://doi.org/10.3402/tellusa.v54i1.12122

Jiang X, Li Y, Yang S, Wu R (2011) Interannual and interdecadal variations of the South Asian and western Pacific subtropical highs and their relationships with Asian-Pacific summer climate. Meteorol Atmos Phys 113:171-180

Jin L, Zhang H, Moise A, Martin G, Milton S, Rodriguez J (2019) Australia-Asian monsoon in two versions of the UK Met Office Unified Model and their impacts on tropical-extratropical teleconnections. Clim Dyn 53(7-8):4717-4741

MacLachlan C et al (2015) Description of GloSea5: the Met Office high resolution seasonal forecast system. Q J R Meteorol Soc 1:1. https://doi.org/10.1002/qj.2396

Martin GM, Milton SF, Senior CA, Brooks ME, Ineson S (2010) Analysis and reduction of systematic errors through a seamless approach to modeling weather and climate. J Clim 23:5933-5957

Nitta T (1987) Convective activities in the tropical western Pacific and their impacts on the Northern Hemisphere summer circulation. J Meteorol Soc Japan 65:373390

Nitta T (1989) Global features of the Pacific-Japan oscillation. Meteorol Atmos Phys 41:5-12. http://doi.org/10.1007/BF01032585

Ning L, Liu J, Wang B (2017) How does the South Asian High influence extreme 
precipitation over eastern China? J Geophys Res Atmos 122:4281-4298

Prakash S, Mitra AK, Momin IM, Rajagopal EN, Milton SF, Martin GM (2016) Skill of short to medium range monsoon rainfall forecasts from two global models over India for hydrometeorological applications. Meteorol Appl 23:574-586

Puri K et al (2013) Implementation of the initial ACCESS numerical weather prediction system. Aust Meteorol Ocean 63:265-284

Ringer MA et al (2006) The physical properties of the atmosphere in the new Hadley Centre global environmental model (HadGEM1). Part II: aspects of variability and regional climate. J Clim 19:1302-1326

Saji NH, Goswami BN, Vinayachandran PN, Yamagata T (1999) A dipole mode in the tropical Indian Ocean. Nature 40:360-363

Sakaguchi K, Lu J, Leung LR, Zhao C, Li Y, \& Hagos S (2016) Sources and pathways of the upscale effects on the Southern Hemisphere jet in MPAS-CAM4 variableresolution simulations. J Adv Model Earth Syst 8(4): 1786 - 1805. https://doi.org/10.1002/2016MS000743

Sardeshmukh P, Hoskins B (1988) The generation of global rotational flow by steady idealized tropical divergence. J Atmos Sci 45:1228-1251

Schneider EK, Watterson IG (1984) Stationary Rossby wave propagation through easterly layers. J Atmos Sci 41:2069-2083

Shaman J, Samelson RM, Tziperman E (2012) Complex wavenumber Rossby wave ray tracing. J Atmos Sci 69:2112-2133

Simmons A J (1982) The forcing of stationary wave motion by tropical diabatic heating. Q J R Meteorol Soc 108:503-534

Sperber KR, Annamalai H, Kang IS, Kitoh A, Moise A, Turner A, Wang B, Zhou T (2013) The Asian summer monsoon: an intercomparison of CMIP5 vs. CMIP3 simulations of the late 20th century. Clim Dyn 41:2711-2744

Walters D et al (2014) The Met Office unified model global atmosphere 4.0 and JULES global land 4.0 configurations. Geosci Model Dev 7:361-386

Walters D et al (2017) The Met Office unified model global atmosphere 6.0/6.1 and 
JULES global land 6.0/6.1 configurations. Geosci Model Dev 10:1487-1520

Walters D et al (2019) The Met Office unified model global atmosphere 7.0/7.1 and JULES global land 7.0 configurations. Geosci Model Dev 12:1909-1963

Wang B, Wu R, Lau K-M (2001) Interannual variability of the Asian summer monsoon: Contrasts between the Indian and the western North Pacific-East Asian monsoons. J. Clim 14:4073-4090

Wei W, Zhang R, Wen M, Rong X, Li T (2014) Impact of Indian summer monsoon on the South Asian High and its influence on summer rainfall over China. Clim Dyn 43:1257-1269

Wei W, Zhang R, Wen M, Kim B-J, Nam J-C (2015) Interannual variation of the South Asian High and its relation with Indian and East Asian summer monsoon rainfall. J Clim 28:2623-2634

Whitham G (1960) A note on group velocity. J Fluid Mech 9:347-352. http://doi.org/10.1017/S0022112060001158

Willetts PD, Marsham JH, Birch CE, Parker DJ, Webster S, Petch J (2017) Moist convection and its upscale effects in simulations of the Indian monsoon with explicit and parametrized convection. Q J R Meteorol Soc 143(703):1073-1085

Williams KD et al (2017) The Met Office Global Coupled model 3.0 and 3.1 (GC3.0 and GC3.1) configurations. J Adv Model Earth Syst 10:357-380

Wilson DR, Ballard SP (1999) A microphysically based precipitation scheme for the UK meteorological office unified model. Q J R Meteorol Soc 125(557):16071636. http://doi.org/10.1002/qi.49712555707

Wood $\mathrm{N}$ et al (2014) An inherently mass-conserving semi-implicit semi-Lagrangian discretization of the deep-atmosphere global non-hydrostatic equations. Q J R Meteorol Soc 140:1505-1520

Wu R (2002) A mid-latitude Asian circulation anomaly pattern in boreal summer and its connection with the Indian and East Asian summer monsoons. Int J Climatol 22:1879-1895

Wu R (2017) Relationship between Indian and east Asian summer rainfall variations. Adv Atmos Sci 34:4-15 
Xing N, Li JP, Li Y (2014) Response of the tropical atmosphere to isolated equatorially asymmetric heating. Chin J Atmos Sci 38(6):1147-1158. https ://doi.org/10.3878/j.issn.1006-9895

Zhang H, McGuffie K, Henderson-Sellers A (1996) Impacts of tropical deforestation II: the role of large-scale dynamics. J. Climate 9:2498-2521

Zhang P, Liu Y, He B (2016) Impact of East Asian summer monsoon heating on the interannual variation of the South Asian High. J Clim 29:159-173

Zhao Y, Huang AN, Zhou Y, Huang DQ (2014) Impact of the middle and upper tropospheric cooling over central Asia on the summer rainfall in the Tarim Basin, China. J Clim 27:4721-4732

Zhao S, Li JP, Li Y (2015) Dynamics of an interhemispheric teleconnection across the critical latitude through a southerly duct during boreal winter. J Clim 28(19):74377456. https ://doi.org/10.1175/JCLI-D-14-00425 .1

Zhao S, Li JP, Li Y, Jin F-F, Zheng J (2018) Interhemispheric influence of Indo-Pacific convection oscillation on Southern Hemisphere rainfall through southward propagation of Rossby waves. Clim Dyn 52(5-6):3203-3221

Zhao Y, Zhang HQ (2016) Impacts of SST warming in tropical Indian Ocean on CMIP5 model-projected summer rainfall changes over Central Asia. Clim Dyn 46:32233238 


\section{Figure captions}

781

782

783

784

785

786

787

788

789

790

791

792

793

794

795

796

797

798

799

800

801

802

803

804

805

806

807

808

Figure 1. Correlation map of JJA rainfall with ISMRI for the period 1982-2008 (a) GPCP; (b) GA7; (c) GA6. (d)-(f) Same as (a)-(c), respectively, but for partial correlation excluding the signals of both ENSO and IOD. Dotted areas denote significance at the $95 \%$ confidence level. The ' $R$ ' at the top right of (b) $-(c)$ indicates the pattern correlation $\left(30^{\circ}-180^{\circ} \mathrm{E}, 50^{\circ} \mathrm{S}-60^{\circ} \mathrm{N}\right)$ with $(\mathrm{a})$, and the ' $\mathrm{R}$ ' at the top right of (e)-(f) indicates the pattern correlation with (b) respectively. The black box denotes the Indian summer monsoon domain $\left(70^{\circ}-90^{\circ} \mathrm{E}, 5^{\circ}-25^{\circ} \mathrm{N}\right)$. The solid black lines represent the pathways of the rainfall teleconnection.

Figure 2. Composites of strong/weak summer monsoon rainfall (JJA) for the period 1982-2008 (unit: mm day ${ }^{-1}$ ). (a), (b) GPCP observations; (c), (d) GA6; (e), (f) GA7; and (g), (h) difference between GA7 and GA6. The black box represents the Indian summer monsoon domain. Cross hatched areas denote significance at the $90 \%$ confidence level. Strong (weak) monsoon years are determined based on when the ISMRI (normalized area-averaged summer rainfall anomalies over $70^{\circ}-90^{\circ} \mathrm{E}, 5^{\circ}-25^{\circ} \mathrm{N}$ ) is above (below) $0.75(-0.75)$.

Figure 3. Map of regression of stream function (shading; units: $\mathrm{m}^{2} \mathrm{~s}^{-1}$ ) and anomalous wind (vectors; units: $\mathrm{m} \mathrm{s}^{-1}$ ) at $500 \mathrm{hPa}$ onto ISMRI (a) ERA-Interim; (c) GA7; (e) GA6. (b), (d), (f) Same as (a), (c), (e), respectively, but for partial regression excluding the signals of both ENSO and IOD. Dotted areas denote significance at the $95 \%$ confidence level; only vectors significant at the $95 \%$ confidence level are shown.

Figure 4. Map of the partial regression of vertical velocity (shading; units: $\mathrm{m} \mathrm{s}^{-1}$ ) and geopotential height anomalies (contour; units: $\mathrm{m}$ ) at $500 \mathrm{hPa}$ onto ISMRI excluding the liner effects of ENSO and IOD (a) ERA-Interim; (b) GA7; (c) GA6. Cross hatched areas denote significance at the $90 \%$ confidence level.

Figure 5. Partial correlation map of JJA rainfall (shading; units: $\mathrm{mm}$ ) and moisture flux at $850 \mathrm{hPa}$ (vectors; units: mm) with ISMRI excluding the signals of ENSO and IOD (a) GPCP; (b) GA7; (c) GA6. Only shading and vectors significant at the $90 \%$ confidence level are shown. 
Figure 6. Map of regression of anomalous horizonal wind (vectors; units: $\mathrm{m} \mathrm{s}^{-1}$ ) at 250 hPa onto ISMRI (a) ERA-Interim; (c) GA7; (e) GA6. (b), (d), (f) Same as (a), (c), (e), respectively, but for partial regression excluding the liner influence of ENSO and IOD. Shaded areas denote significance at the $90 \%$ confidence level.

Figure 7. Stationary Rossby wave ray trajectories (curves) initiated with zonal wavenumbers 2-5 from ISMR sources (black dots), driven by the $250 \mathrm{hPa}$ horizontal wind, and excluding the influence of ENSO and the IOD. (a)-(c) ERA-Interim wind data; (d)-(f) GA6; and (g)-(i) GA7. Red and green curves represent the stationary Rossby waves propagating in the Southern and Northern Hemisphere, respectively.

Figure $8.250 \mathrm{hPa}$ climatological zonal winds (contours; unit: $\mathrm{m} \mathrm{s}^{-1}$ ) and meridional winds (shading; unit: $\mathrm{m} \mathrm{s}^{-1}$ ) excluding the influence of ENSO and the IOD. (a) ERAInterim; (b) GA7; (c) GA6; (d) difference between GA7 and GA6. Difference between GA6 and observations of composite meridional winds from years of (e) weak and (f) strong ISMR. Difference between GA7 and GA6 of composite meridional winds from years of (g) weak and (h) strong ISMR. Dotted areas represent significance at the $90 \%$ confidence level.

Figure 9. Multiple regression of $200 \mathrm{hPa}$ meridional wind to (a)-(c) ISMRI and (d)-(f) SAHI. (g)-(f) Meridional geostrophic wind (shading; units: $\mathrm{m} \mathrm{s}^{-1}$ ) and geopotential height (contour; units: $\mathrm{m}$ ). The solid lines in (g)-(i) represent the location of the climatological SAH, and the yellow and purple thick solid lines in (d)-(f) indicate the composites location of SAH in the years of strong and weak ISMR. Top column is for ERA-Interim, middle column is for GA7, and bottom column is for GA6. 


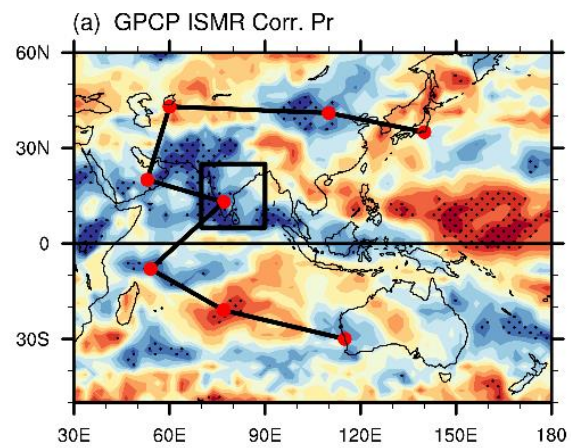

(d) GPCP partial ENSO and IOD
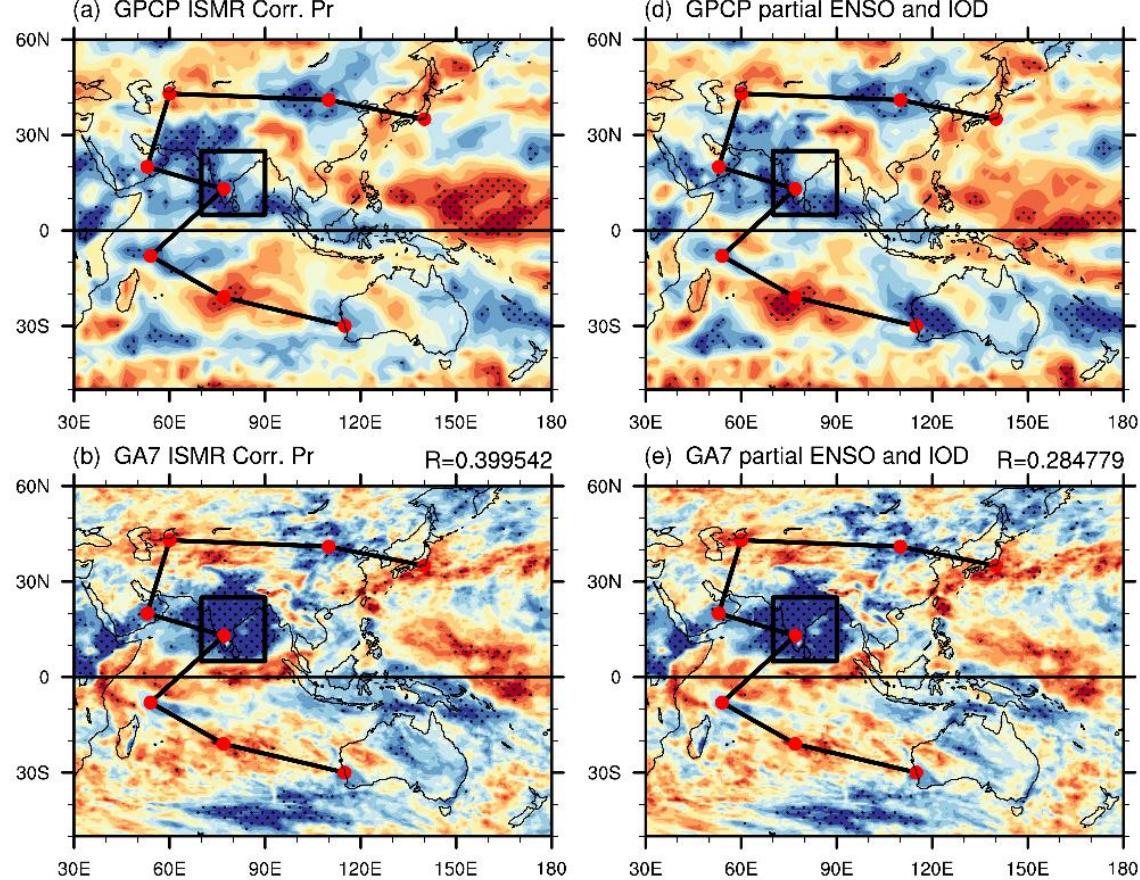

(e) GA7 partial ENSO and IOD $R=0.284779$
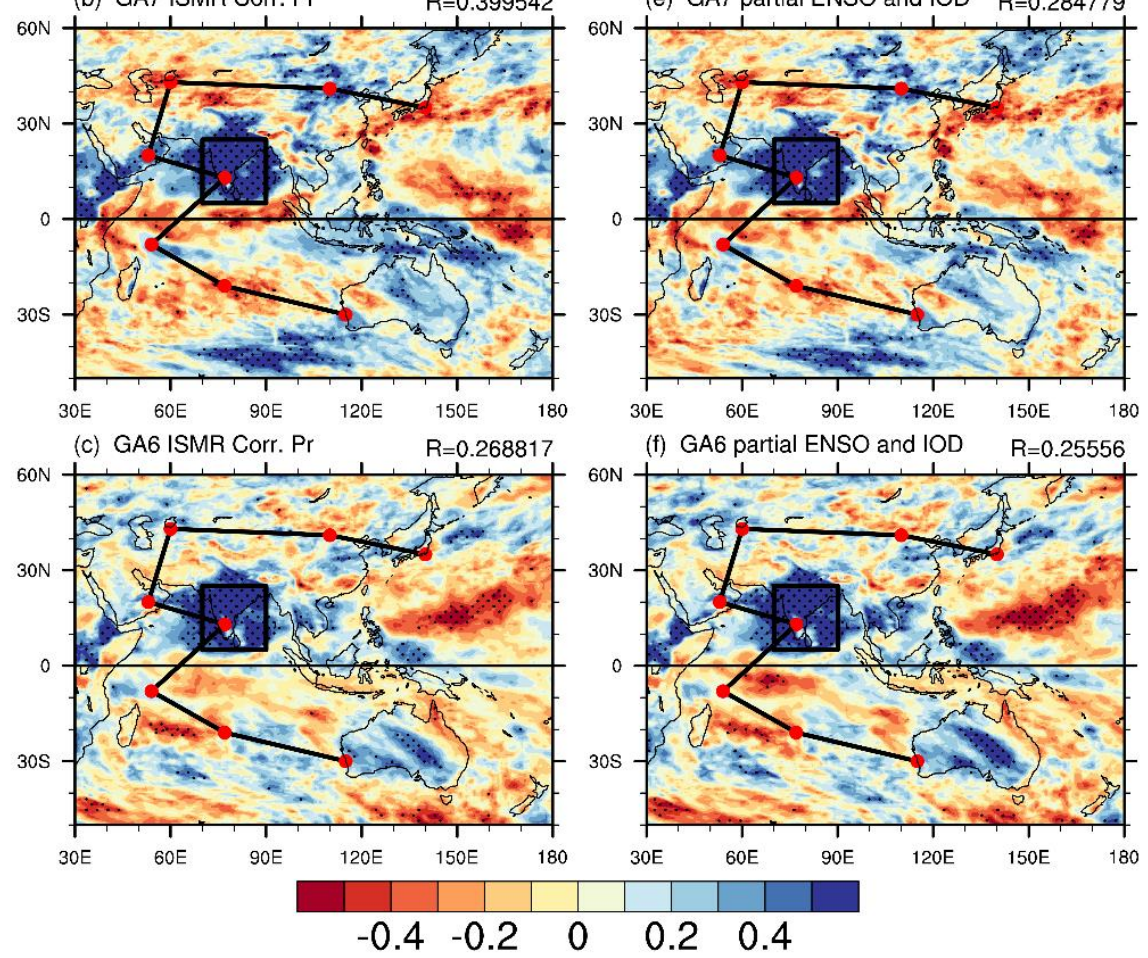

Fig. 1. Correlation map of JJA rainfall with ISMRI for the period 1982-2008 (a) GPCP; (b) GA7; (c) GA6. (d)-(f) Same as (a)-(c), respectively, but for partial correlation excluding the signals of both ENSO and IOD. Dotted areas denote significance at the $95 \%$ confidence level. The ' $R$ ' at the top right of $(b)-(c)$ indicates the pattern correlation

$837\left(30^{\circ}-180^{\circ} \mathrm{E}, 50^{\circ} \mathrm{S}-60^{\circ} \mathrm{N}\right)$ with $(\mathrm{a})$, and the ' $\mathrm{R}$ ' at the top right of (e)-(f) indicates the 838 pattern correlation with (b) respectively. The black box denotes the Indian summer monsoon domain $\left(70^{\circ}-90^{\circ} \mathrm{E}, 5^{\circ}-25^{\circ} \mathrm{N}\right)$. The solid black lines represent the pathways of the rainfall teleconnection. 
(a) Obs_Weak_Pr
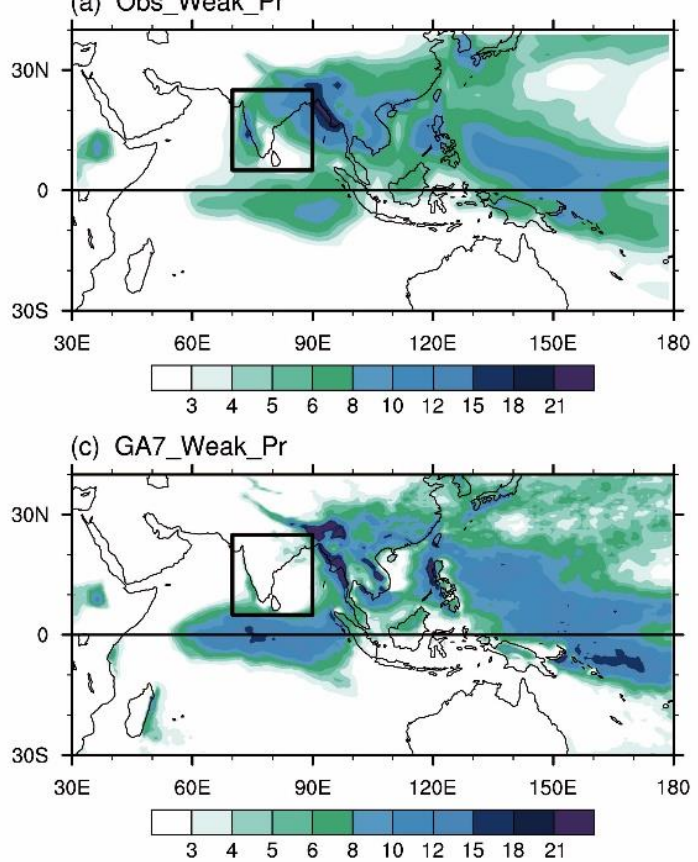

(e) GA6_Weak_Pr
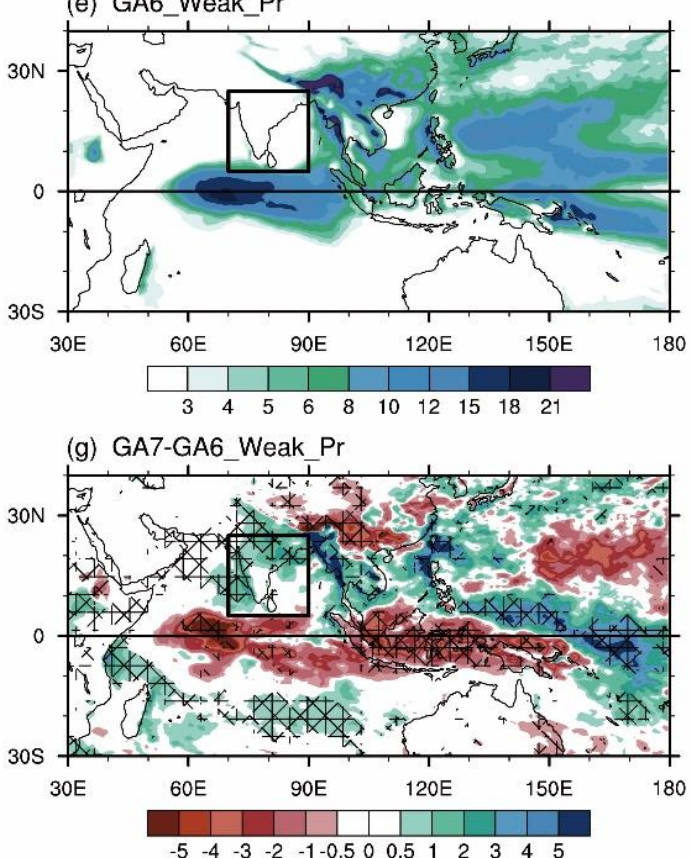

(b) Obs_Strong_Pr
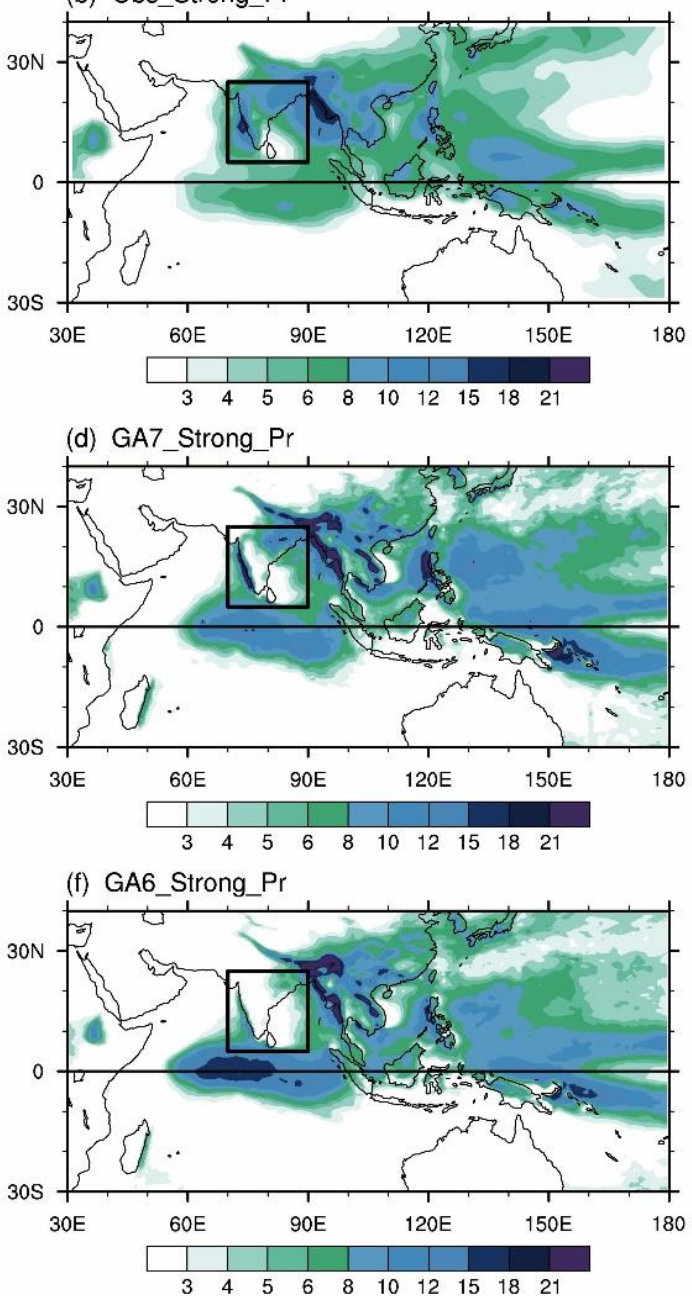

(h) GA7-GA6_Strong_Pr

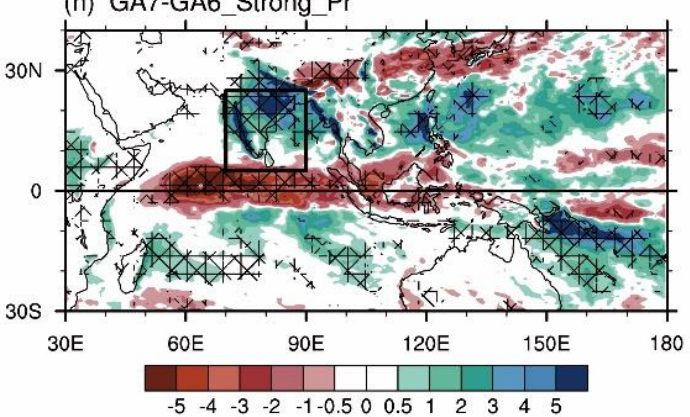

842

Fig. 2. Composites of strong/weak summer monsoon rainfall (JJA) for the period 19822008 (unit: mm day ${ }^{-1}$ ). (a), (b) GPCP observations; (c), (d) GA6; (e), (f) GA7; and (g), (h) difference between GA7 and GA6. The black box represents the Indian summer monsoon domain. Cross hatched areas denote significance at the $90 \%$ confidence level. Strong (weak) monsoon years are determined based on when the ISMRI (normalized area-averaged summer rainfall anomalies over $70^{\circ}-90^{\circ} \mathrm{E}, 5^{\circ}-25^{\circ} \mathrm{N}$ ) is above (below) $0.75(-0.75)$ 
(a) GPCP ISMR reg at Z500

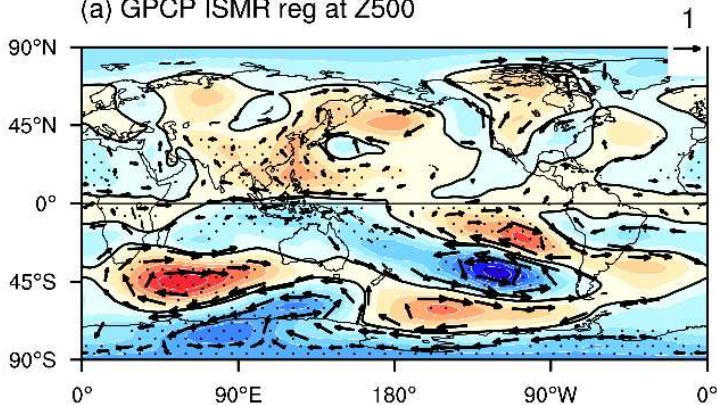

(c) GA7 ISMR reg at Z500 (b) GPCP ISMR partial reg at Z500

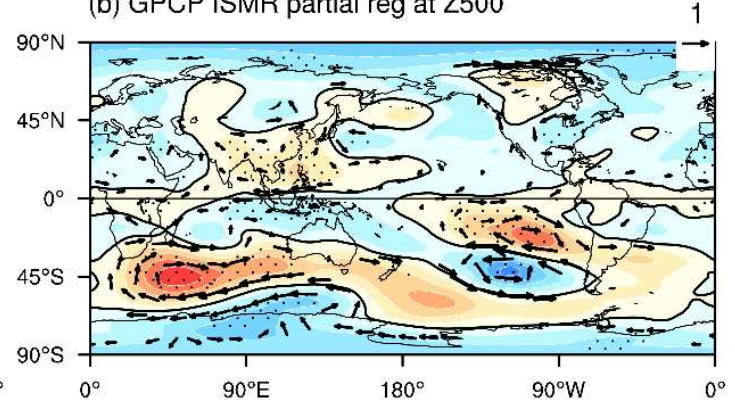

(d) GA7 ISMR partial reg at Z500

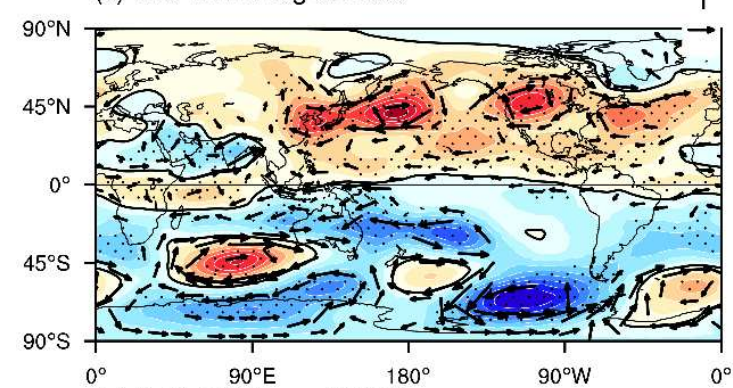

(e) GA6 ISMR reg at Z500
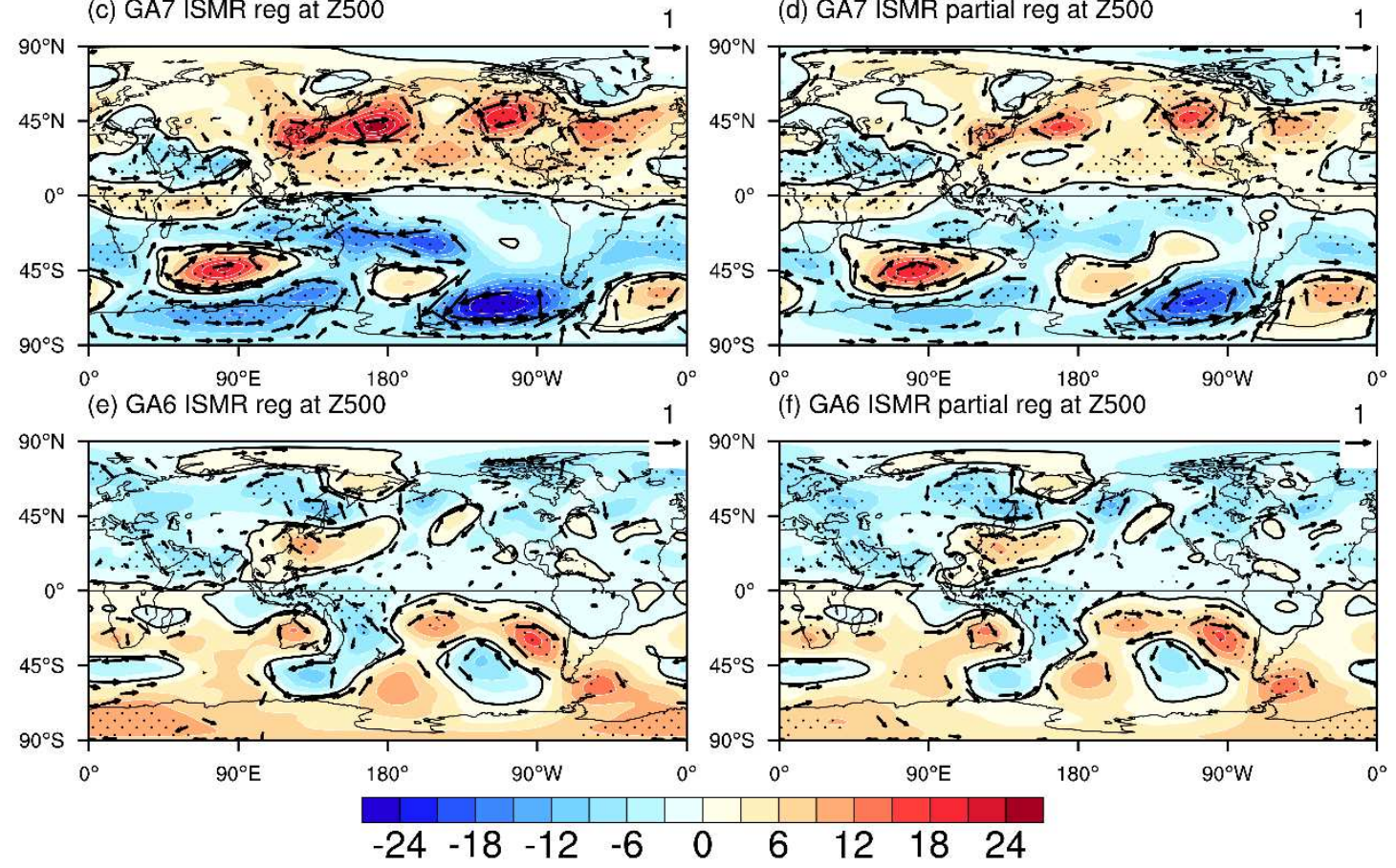

850

851 Fig. 3. Map of regression of stream function (shading; units: $\mathrm{m}^{2} \mathrm{~s}^{-1}$ ) and anomalous

852 wind (vectors; units: $\mathrm{m} \mathrm{s}^{-1}$ ) at $500 \mathrm{hPa}$ onto ISMRI (a) ERA-Interim; (c) GA7; (e) GA6.

853 (b), (d), (f) Same as (a), (c), (e), respectively, but for partial regression excluding the

854 signals of both ENSO and IOD. Dotted areas denote significance at the 95\% confidence

855 level; only vectors significant at the 95\% confidence level are shown. 
(a) Obs

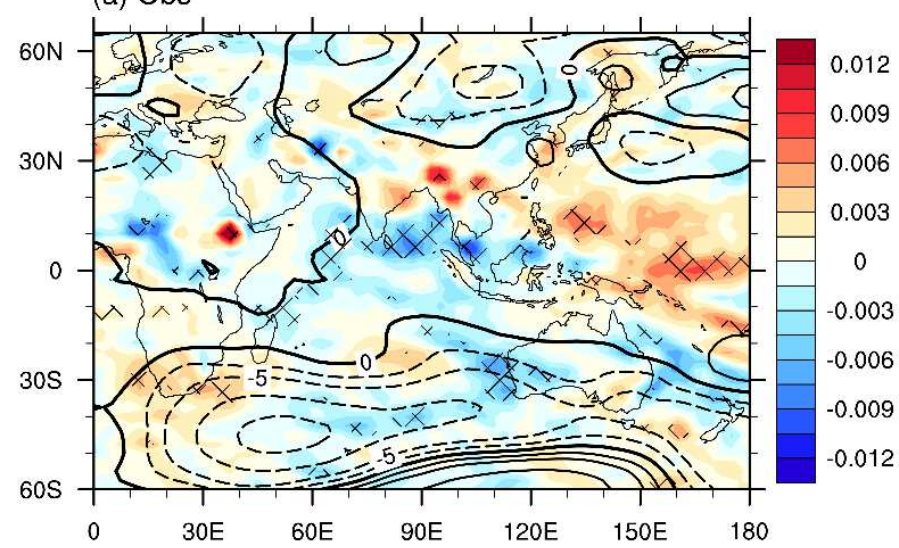

(b) GA7

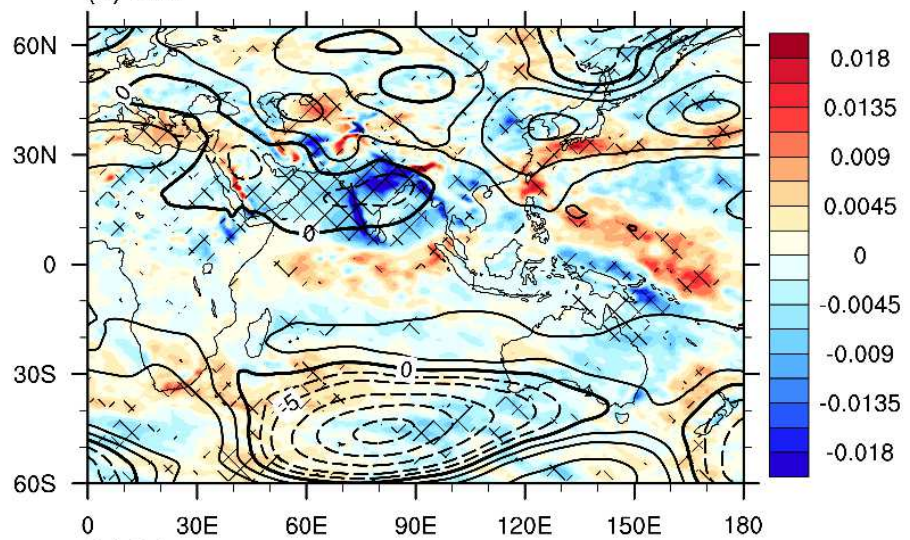

(c) GA6

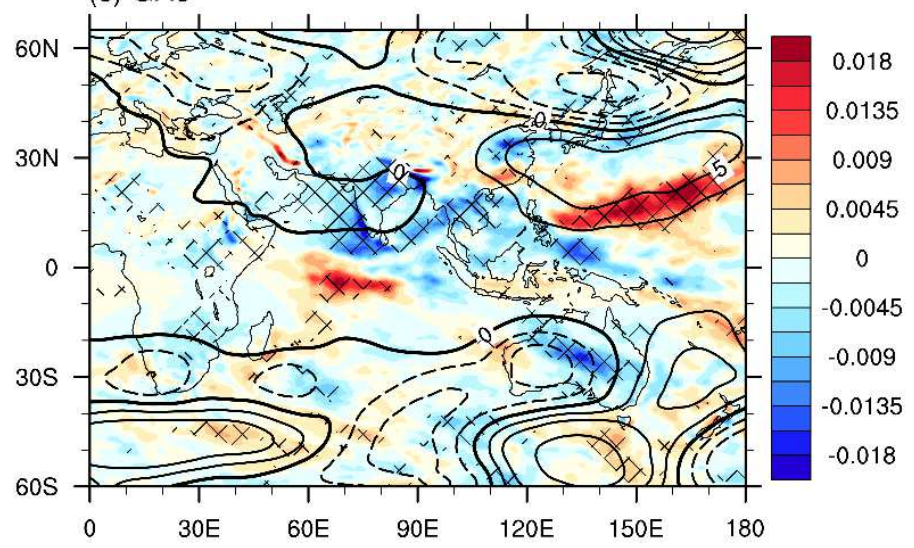

857 Fig. 4. Map of the partial regression of vertical velocity (shading; units: $\mathrm{m} \mathrm{s}^{-1}$ ) and 858 geopotential height anomalies (contour; units: $\mathrm{m}$ ) at $500 \mathrm{hPa}$ onto ISMRI excluding the 859 liner effects of ENSO and IOD (a) ERA-Interim; (b) GA7; (c) GA6. Thick solid lines 860 indicate the zero lines. Cross hatched areas denote significance at the $90 \%$ confidence 861 level. 
(a) Obs Partial Corr Pr and Water Vapour at Z850

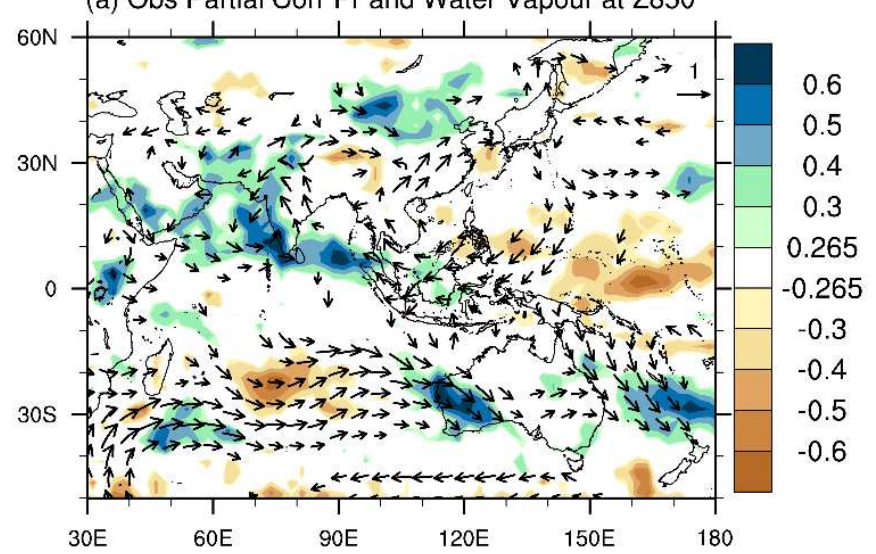

(b) GA7 Partial Corr Pr and Water Vapour at Z850

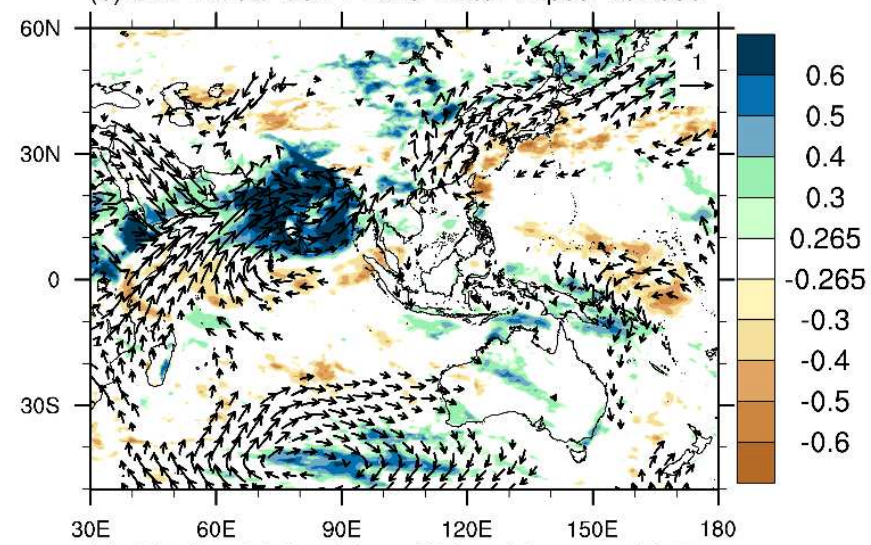

(c) GA6 Partial Corr Pr and Water Vapour at Z850

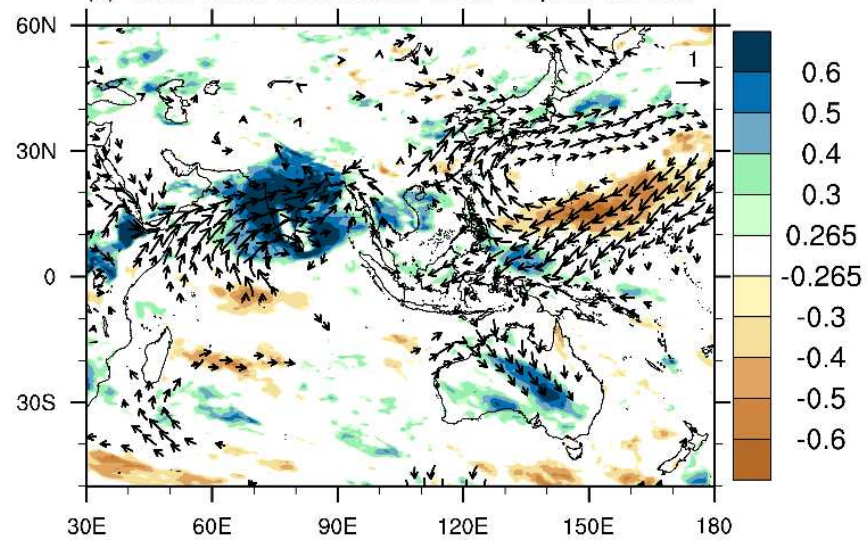

863 Fig. 5. Partial correlation map of JJA rainfall (shading; units: $\mathrm{mm}$ ) and moisture flux at

$864850 \mathrm{hPa}$ (vectors; units: $\mathrm{mm}$ ) with ISMRI excluding the signals of ENSO and IOD (a)

865 GPCP; (b) GA7; (c) GA6. Only shading and vectors significant at the $90 \%$ confidence

866 level are shown. 
(a) Obs ISMR reg UV_250_hPa

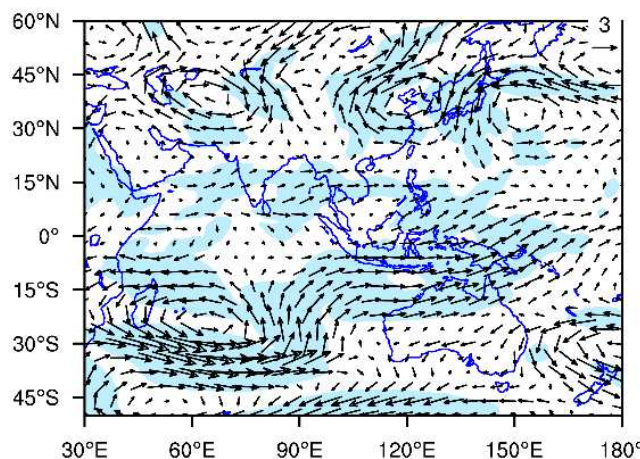

(c) GA7 ISMR reg UV_250_hPa $\mathrm{m} / \mathrm{s}$

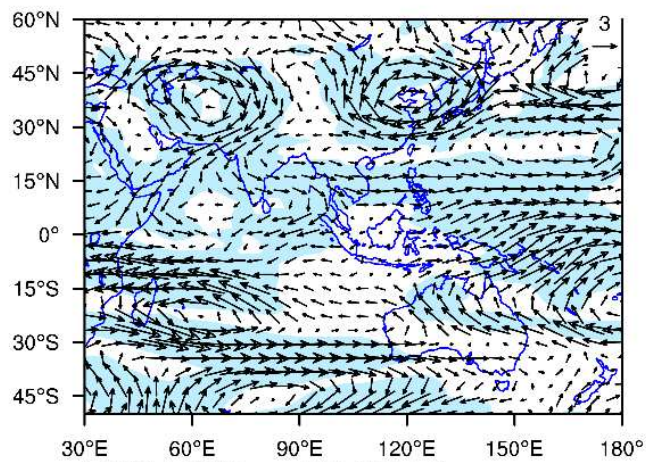

(e) GA6 ISMR reg UV_250_hPa $\mathrm{m} / \mathrm{s}$

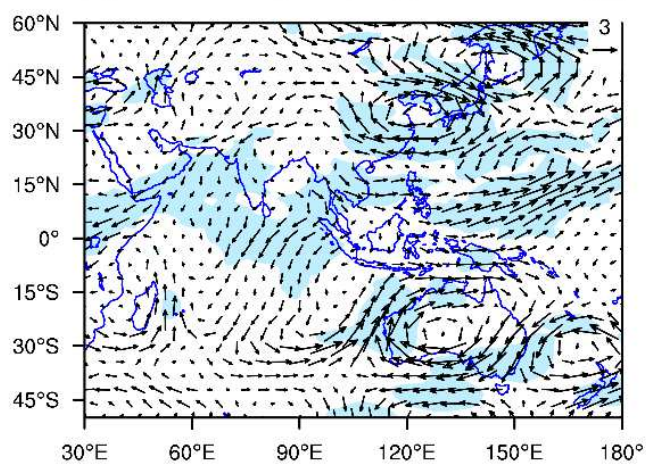

(b) Obs Partial ISMR reg UV_250_hPa $\mathrm{m} / \mathrm{s}$

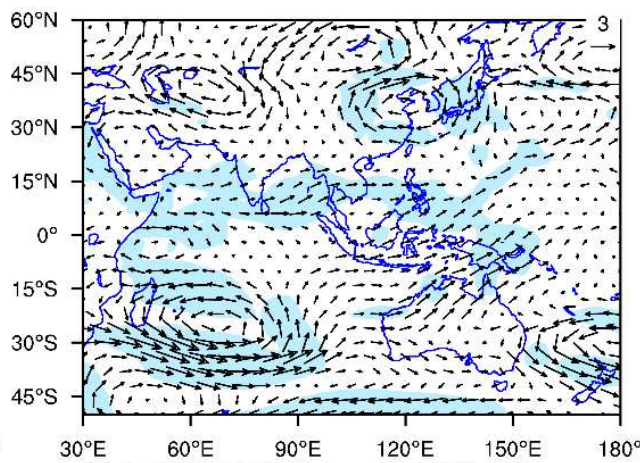

(d) GA7 ISMR Partial reg UV_250_hPa $\mathrm{m} / \mathrm{s}$

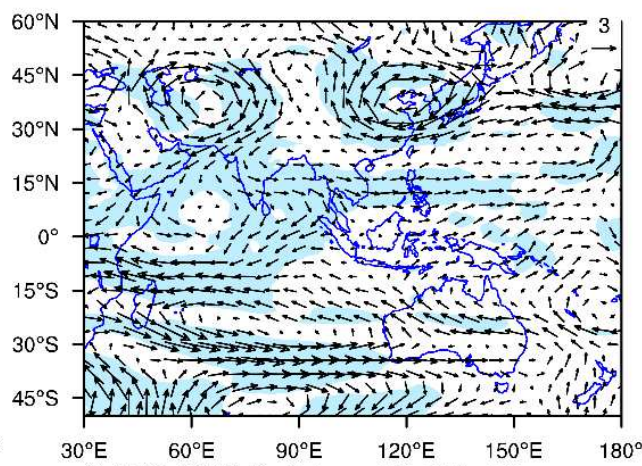

(f) GA6 ISMR Partial reg UV_250_hPa $\mathrm{m} / \mathrm{s}$

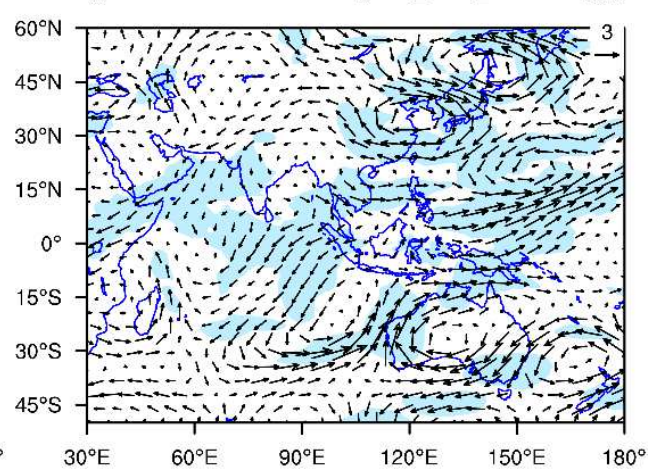

Fig. 6. Map of regression of anomalous horizonal wind (vectors; units: $\mathrm{m} \mathrm{s}^{-1}$ ) at 250

869 hPa onto ISMRI (a) ERA-Interim; (c) GA7; (e) GA6. (b), (d), (f) Same as (a), (c), (e),

870 respectively, but for partial regression excluding the liner influence of ENSO and IOD.

871 Shaded areas denote significance at the 90\% confidence level. 
(a) Obs_Climate mean

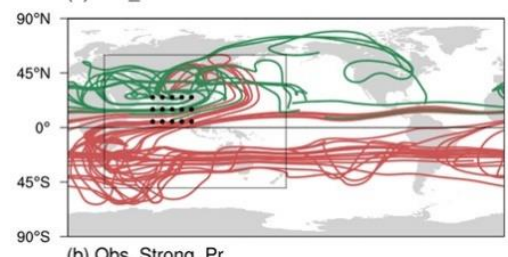

$90^{\circ} \mathrm{S}$ (b) Obs_Strong_Pr

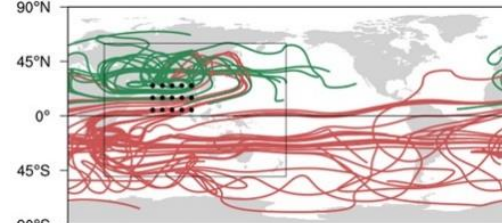

$90^{\circ} \mathrm{S}$ (c) Obs_Weak_Pr

${ }^{90^{\circ} \mathrm{N}} \mathrm{N}$

$0^{\circ}+2$

$45^{\circ} \mathrm{S}$

$90^{\circ} \mathrm{S}$

872

873

874

875

876

877

878 (d) GA7_Climate mean

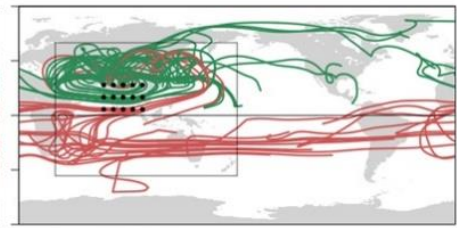

(e) GA7_Strong_Pr

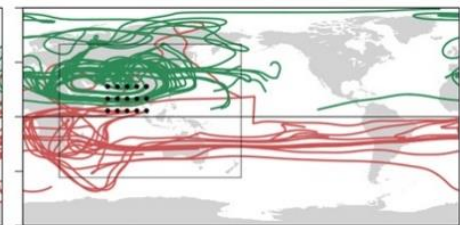

(f) GA7_Weak_Pr

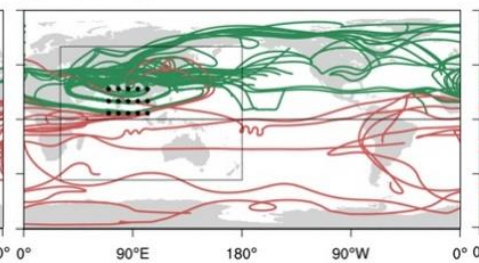

(g) GA6 Climate mean

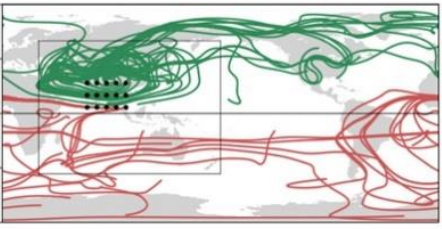

(h) GA6_Strong_Pr

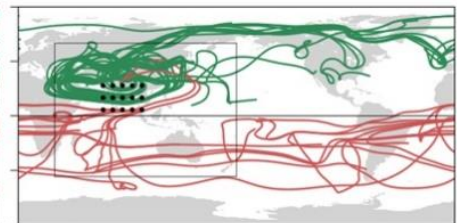

(i) GA6_Weak_Pr

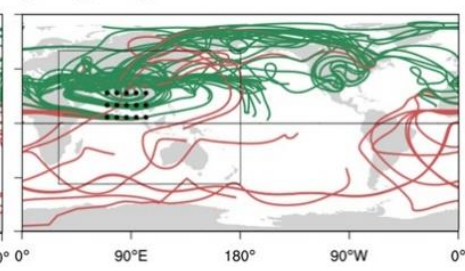

Fig. 7. Stationary Rossby wave ray trajectories (curves) initiated with zonal wavenumbers 2-5 from ISMR sources (black dots), driven by the $250 \mathrm{hPa}$ horizontal wind, and excluding the influence of ENSO and the IOD. (a)-(c) ERA-Interim wind data; (d)-(f) GA6; and (g)-(i) GA7. Red and green curves represent the stationary Rossby waves propagating in the Southern and Northern Hemisphere, respectively. 
(a) Obs

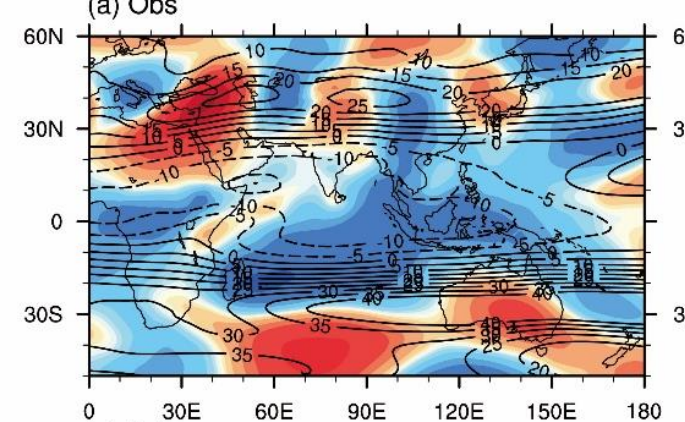

(c) GA6

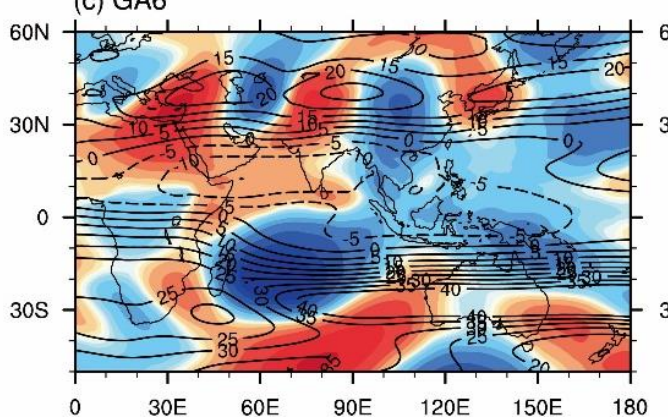

(e) weak GA6-Obs
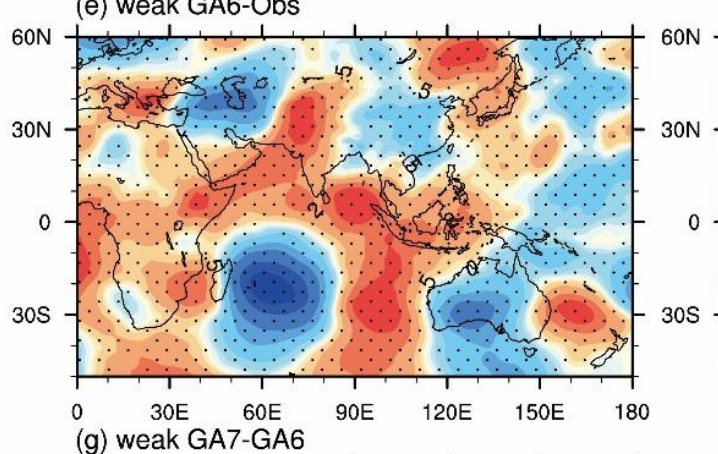

(b) GA7

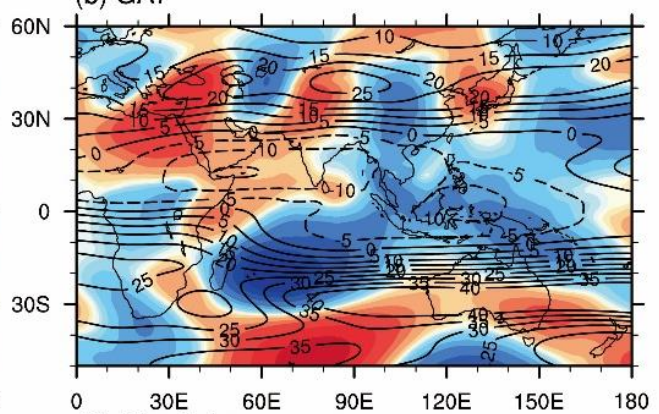

(d) GA7-GA6

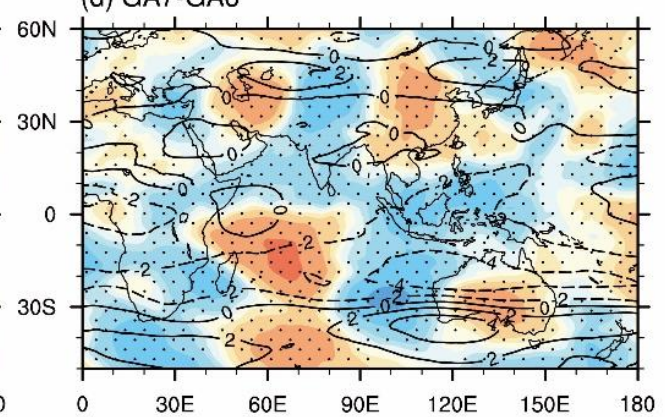

(f) strong GA6-Obs

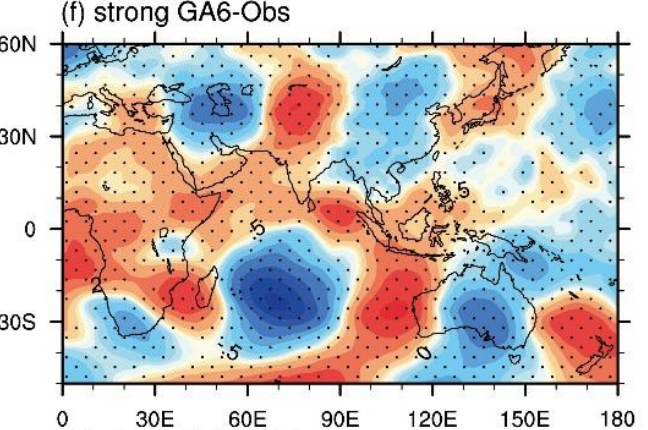

(h) strong GA7-GA6

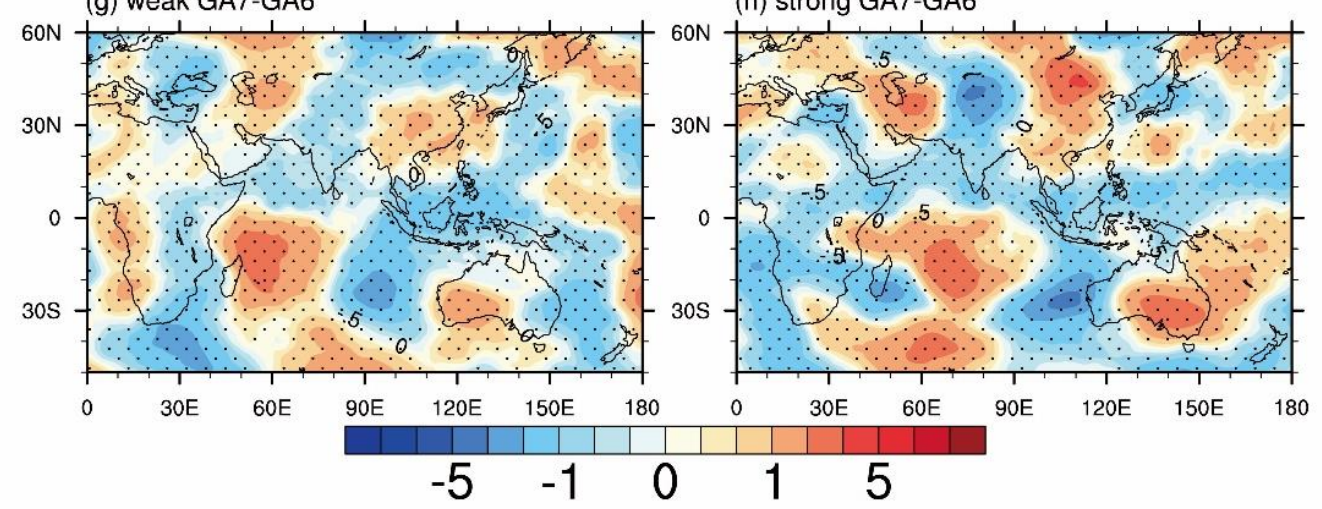

Fig. 8. $250 \mathrm{hPa}$ climatological zonal winds (contours; unit: $\mathrm{m} \mathrm{s}^{-1}$ ) and meridional winds

881 (shading; unit: $\mathrm{m} \mathrm{s}^{-1}$ ) excluding the influence of ENSO and the IOD. (a) ERA-Interim;

882 (b) GA7; (c) GA6; (d) difference between GA7 and GA6. Difference between GA6 and

883 observations of composite meridional winds from years of (e) weak and (f) strong

884 ISMR. Difference between GA7 and GA6 of composite meridional winds from years

885 of $(\mathrm{g})$ weak and $(\mathrm{h})$ strong ISMR. Dotted areas represent significance at the $90 \%$

886 confidence level. 

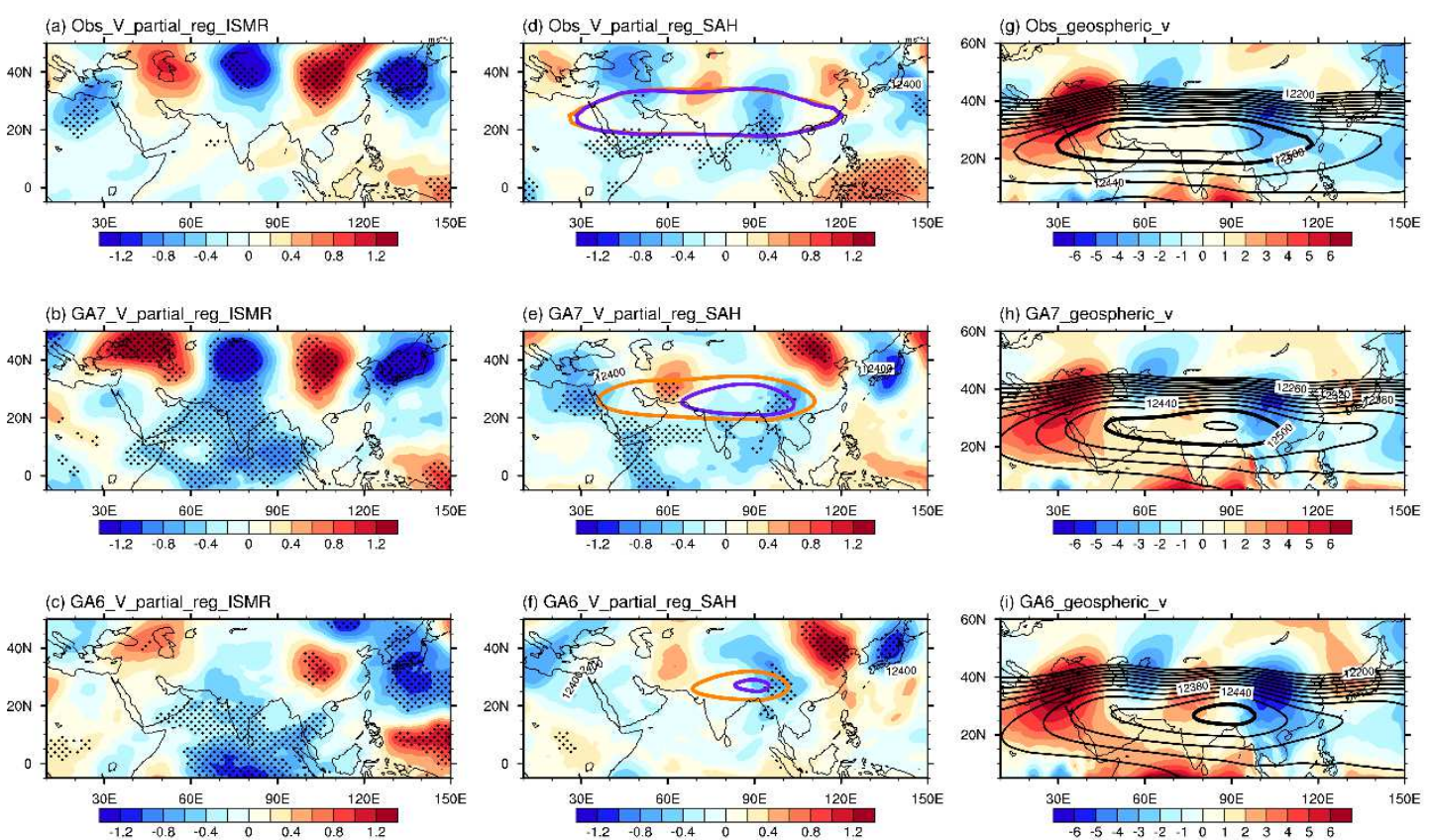

888 Fig. 9. Multiple regression of $200 \mathrm{hPa}$ meridional wind to (a)-(c) ISMRI and (d)-(f)

889 SAHI. (g)-(f) Meridional geostrophic wind (shading; units: $\mathrm{m} \mathrm{s}^{-1}$ ) and geopotential 890 height (contour; units: $\mathrm{m}$ ). The solid lines in (g)-(i) represent the location of the 891 climatological SAH, and the yellow and purple thick solid lines in (d)-(f) indicate the 892 composites location of SAH in the years of strong and weak ISMR. Top column is for 893 ERA-Interim, middle column is for GA7, and bottom column is for GA6. 